\title{
Efeito metrópole e acesso às oportunidades educacionais*
}

\author{
LUIZ CÉSAR DE QUEIROZ RIBEIRO, MARIANE CAMPELO KOSLINSKI** \\ ** Universidade Federal do Rio de Janeiro
}

\begin{abstract}
This article explores a hypothesis of the impact of social issues on the reproduction of inequalities in educational opportunities in the context of Brazilian metropolises. Reflections on the metropolitanization of social issues have been developed in terms of tendencies such as the weakening of labour market ties and the family and community as realms of non-commercial protection and reproduction, combined with processes of urban segmentation and segregation. These tendencies have been observed in a more pronounced way in the larger urban agglomerations. In order to develop the analysis, national basic education evaluation (Prova Brasil) and School Census databases (2005) have been used, as well as data from the National Census - IBGE (2000). Based on the results, the article proposes possible explanations to the patterns found and seeks to contribute to the formulation of a research agenda on the "metropolitan-effect" on educational opportunities.
\end{abstract}

KEY WORDS: metropolitan areas, social inequality, segregation

RESUMO Este trabalho explora a hipótese do impacto da metropolização da questão social no Brasil sobre a reprodução de desigualdades de oportunidades educacionais. A tendência de metropolização da questão social é pensada a partir da combinação entre a fragilização dos laços com o mercado de trabalho e do universo da família e da comunidade como esferas da reprodução e proteção não-mercantil, combinados a processos de segmentação e segregaçáo urbana, tendências observadas de maneira acentuada nos grandes aglomerados urbanos. Para a análise, utiliza dados referentes à Prova Brasil e ao Censo Escolar 2005, bem como dados do Censo 2000 do IBGE. A partir dos resultados, propóe possíveis explicaçóes para os padrões encontrados e pretende contribuir para a formulação de uma agenda de estudos de um "efeitometrópole" sobre oportunidades educacionais.

PALAVRAS-CHAVE: áreas metropolitanas, desigualdade social, segregação

\footnotetext{
* Recibido el 14 de abril de 2009, aprobado el 17 de septiembre de 2009.

Correspondencia: Luiz Cesar de Queiroz Ribeiro, Prédio da Reitoria, Sala 543- Cidade Universitária, Ilha do Fundão, Rio de Janeiro, Brasil. E-mail: lcqribeiro@gmail.com. Mariane Campelo Koslinski, Rua Candido Mendes 383 apto. 501, CEP 20241-220 - Rio de Janeiro - RJ, Brasil. E-mail: marianeck@yahoo.com
} 


\section{Introduçáo}

A preocupação com as igualdades de oportunidades educacionais como forma de garantir maior igualdade social já vem de longa data. A partir da segunda Guerra Mundial, frente à disseminação de valores igualitários e aos crescentes conflitos sociais, diversos estudos no campo da sociologia da educação passam a tratar de temas relacionados à capacidade da educação promover mobilidade e maior igualdade (Karabel \& Halsey, 1977).

Uma primeira geração de estudos baseados em grandes surveys resultou na conclusão sobre a incapacidade da Escola reverter as desigualdades geradas pelas origens socioeconômicas dos alunos. Uma segunda geração, se contrapondo à primeira, tentou mostrar que a Escola pode fazer a diferença sobre resultados escolares. Entretanto, podemos considerar a emergência, nas últimas décadas, de uma terceira geração de estudos, cuja característica é a conjugação das abordagens da sociologia urbana e da sociologia da educação para tratar dos possíveis efeitos dos contextos sociais conformados pela organização social do território sobre as condiçóes efetivas de escolarização de crianças e jovens.

A primeira geração de estudos foi financiada por governos que pretendiam ampliar e reformar os seus sistemas de educação. Um dos mais influentes foi o relatado no Coleman Report (1966), que observou que a variabilidade no interior de uma escola é maior do que entre as escolas e conclui que as diferenças de resultados se devem mais às diferenças da clientela das escolas do que diferenças das características escolares (recursos, equipamentos, programas, qualificação dos professores) ${ }^{1}$. O debate gerado por esse relatório provocou reaçóes e críticas em círculos acadêmicos e de decisóes políticas, dado o pessimismo de suas conclusóes quanto à capacidade da escola de reverter efeitos da origem socioeconômica das famílias (Reynolds $\&$ Teddlie, 2000; Soares, 2002).

Em resposta a estes estudos uma segunda geração de estudos visou à abertura da "caixa preta" das escolas. Estudos da escola eficaz (effective school) e do efeito-escola (school effect) passaram a defender o lema de que a "escola faz diferença" e que podia exercer efeito sobre as oportunidades educacionais. Estes estudos concentraram seus esforços na tarefa de determinar quais fatores escolares poderiam levar a um maior ou menor desempenho escolar. É interessante notar que estes estudos têm um fundamento pragmático, já que visam prover elementos que possam auxiliar políticas educacionais a alcançarem maior eficácia e equidade de resultados.

Se antes estudos no âmbito da sociologia da educação tratavam somente do efeito da família e da escola, nas últimas décadas uma terceira geração de estudos, com a exacerbação dos fenômenos de guetificação nas grandes cidades, têm buscado conjugar abordagens da sociologia urbana e da sociologia da educação para tratar fatores relacionados à organização social do território e seus possíveis efeitos sobre as oportunidades educacionais. Ganha relevância nos estudos sobre as possibilidades da eficácia e da equidade da escola os possíveis efeitos dos contextos

1 Na Grã-Bretanha o relatório Plowden (1967) chegaria a resultados similares: variáveis escolares teriam menor impacto na explicação de diferenças de sucesso escolar nas escolas primárias se comparadas com fatores ligados às atitudes e comportamento dos pais (Forquin, 1995). 
sociais formados pelas unidades de vizinhança constituídas pelos processos de agregação e segregação residenciais. Este tema retoma antigas preocupaçôes da sociologia clássica a respeito dos determinantes contextuais da trajetória dos indivíduos na sociedade, sob o impulso das rápidas e intensas mudanças ocorridas nas grandes cidades, em especial as americanas, com a transformação sócio-econômica impulsionada pela globalização e a re-estruturação do capitalismo industrial. As duas principais marcas de tais mudanças é a constituição de territórios com forte concentração de pobres em áreas estagnadas economicamente e apresentando evidentes sinais de desorganização social, isolamento do restante da sociedade, desertificação cívica, criminalidade violenta, diminuição da eficácia normativa nas interaçóes sociais, com enormes impactos sobre as instituiçóes sociais localizadas nestes territórios.

O Brasil vem passando por crescente processo de universalização do ensino fundamental. Segundo a PNAD de 2007, 97,6\% da população com idade de 7 a 14 anos freqüentavam a escola. Este percentual não é significativamente diferente nas regióes, pois alcança $98 \%$ nas regiōes Sudeste, Sul e Centro-Oeste; $97,1 \%$ no Nordeste e 96,2\% no Norte. No entanto, os dois grandes desafios enfrentados são os relacionados ao aumento da eficácia da equidade do sistema escolar.

A universalização do ensino básico e a existência de avaliaçóes sistemáticas - SAEBs, Prova Brasil 2005 e 2007, IDEB - têm incentivado estudos sobre os fatores que explicam a eficácia escolar. Segundo Lee, Franco e Albinas (2004) as pesquisas têm considerado os seguintes fatores: (a) recursos escolares; (b) organização e gestão da escola; (c) clima acadêmico; (d) formação e salário docente; (e) ênfase pedagógica. Segundo tais autores, a composição social da escola é considerada como variável de controle, pois a pesquisa está focada na identificação daqueles fatores intrínsecos ao seu funcionamento.

Entretanto, no contexto brasileiro, observamos a existência de poucos estudos que se dediquem a avaliar a eficácia escolar considerando os efeitos dos contextos sociais extra-escolar. Os primeiros estudos com esta preocupação foram de Alves, Franco e Ribeiro (2008), Torres et al. (2008), Soares, Rigotti e Andrade (2008) que focalizam diferenças intra-municipais no Rio de Janeiro, São Paulo e Belo Horizonte, respectivamente.

No que diz respeito a diferenças entre municípios, recentemente, Alves (2007) pesquisou a eficácia escolar nas capitais brasileiras no período de 1996 a 2005. Dois tipos de fatores foram especialmente tratados naquele trabalho: os decorrentes das profundas alterações dos fluxos escolares, que levou às escolas segmentos sociais tradicionalmente alijados, e os relacionados com o processo de municipalização do ensino básico, o que ensejou a diversificação prática das políticas educacionais no ensino básico. Os resultados gerais do trabalho indicam que enquanto no conjunto do Brasil ocorreu a queda de 7,5 no desempenho escolar no período 1995/2003 na escala do SAEB, nas capitais a qualidade da escola manteve-se estável.

O principal objetivo deste trabalho é contribuir nessa direção. Estamos interessados em avaliar como o contexto social da vida nas grandes cidades pode influenciar o desempenho do sistema escolar municipal. Mais especificamente, o trabalho investiga o efeito das tendências da metropolização da questão social sobre as desigualdades de acesso às oportunidades educacionais. 
Na primeira sessão discute brevemente a literatura norte-americana que focaliza a importância do contexto social sobre a eficácia escolar. Em seguida discute a pertinência de se pensar a metropolização da questão social no Brasil como decorrência da combinação entre a fragilização dos laços com o mercado de trabalho formalizado dos trabalhadores menos qualificados e do universo da família e da comunidade como esferas da reprodução e proteção não-mercantil, combinados a processos de segmentação e segregação urbana, para compreender as desigualdades de oportunidades educacionais entre municípios metropolitanos e não metropolitanos. $\mathrm{Na}$ terceira sessão apresenta os modelos e as análises construídas para capturar um possível efeito-metrópole sobre oportunidades educacionais na realidade brasileira. Por último, propóe alguns temas de discussão e, sobretudo, apresenta algumas linhas de exploração empírica com as quais desdobraremos esta investigação.

\section{A metropolização da questáo social: o contexto brasileiro}

A sociologia urbana nasce como disciplina sob a influência dos clássicos trabalhos da chamada "escola de Chicago" que, examinando os processos de segregação residencial de grupos sociais homogêneos ética e culturalmente, construiu referências conceituais e metodológicas sobre os efeitos dos contextos sociais de vizinhança sobre os processos de assimilação dos indivíduos na ordem social competitiva. Após o longo período de eclipse da influência dos trabalhos de William I. Thomas, Florian Znaniecki, Robert E. Park, Louis Wirth, Ernest Burgess, Everett Hughes e Robert McKenzie, com a hegemonia da sociologia de Talcoltt Parson, o tema é retomado nos anos 1980 com a repercussão do seminal trabalho de Wilson (1987). A sua teorização sobre os efeitos reprodutores das desvantagens sociais decorrentes da concentração territorial dos antigos operários negros transformados em excluídos da mainstream da economia resultante da reestruturação produtiva exerceu grande influencia na realização de uma série de estudos fundados na sua hipótese de que a pobreza da vizinhança afeta as oportunidades dos mais pobres $^{2}$. Estes estudos buscaram compreender certos desfechos sociais a partir de uma relação de causalidade entre o indivíduo (motivações, escolhas, comportamentos e situação social) e os contextos sociais de onde reside, caracterizados principalmente a partir de propriedades comuns de seus residentes.

Como por exemplo, no campo da sociologia da educação, se antes estudos que tentavam explicar desigualdade de resultados educacionais se concentravam em fatores relacionados à família e à escola, a partir da década de 1990 observamos a proliferação de estudos que passam a considerar a vizinhança como esfera também capaz de exercer impacto sobre a distribuição de oportunidades educacionais.

Duas questóes principais norteiam a vasta literatura sobre efeito vizinhança que segue o estudo de Wilson (1987): a) que condições da vizinhança afetam resultados individuais, como por

2 De acordo com Wilson (1987) a conjunção de fatores tais como mudanças estruturais na economia, o crescimento da desigualdade e a saída seletiva de famílias das classes média e trabalhadora negras para vizinhanças de alta renda e para os subúrbios levou à concentração da pobreza dentro de vizinhanças de minorias pobres e teria levado a um ambiente de escassez de instituiçóes, valores, modelos de papel social que seriam necessários para alcançar sucesso em uma sociedade pós industrial. 
exemplo, resultados escolares? b) quais mecanismos explicam a relação entre as características do bairro e resultados individuais?

Diversas revisões bibliográficas já foram realizadas a respeito dos mecanismos que explicam o impacto negativo das vizinhanças pobres e/ou o impacto positivo de vizinhanças afluentes (Jencks \& Mayer, 1990; Ellen \& Turner, 1997; Brooks- Gun et al., 1997, Sampson \& Morenoff, 2002; Small \& Newman, 2001). No que diz respeito aos efeitos sobre oportunidades educacionais, as explicaçóes por parte da demanda da educação, ou os modelos de socialização coletiva ${ }^{3}$ prevalecem (Jencks \& Mayer, 1990) em detrimento de explicaçóes que privilegiam modelos institucionais ${ }^{4}$ ou o lado da oferta da educação (Ribeiro \& Koslinski, 2009).

No que diz respeito às condiçóes da vizinhança e seus resultados escolares, observamos uma grande variedade de formas utilizadas para operacionalizar variáveis capazes de dar conta das relaçóes sociais nas vizinhanças ou bairros, ou para captar as desigualdades dentro de grandes cidades ou de metrópoles decorrente da segregação residencial ${ }^{5}$.

Como exemplo, podemos citar estudos que observam transformaçóes da morfologia social de cidades em contextos urbanos latino-americanos e que se aproximam das explicaçóes sobre os processos observados por Wilson (1987) no contexto norte-americano. Essas transformaçóes implicaram na modificação da composição social dos bairros, que se tornam cada vez mais socioeconomicamente homogêneos e conformam espaços isolados uns dos outros. Essa segregação residencial em grande escala, ou do tipo centro-periferia em que vizinhanças pobres e assentamentos irregulares são construídos em áreas periféricas, levariam à diminuição de oportunidades de interação entre pessoas ocupando diferentes posiçóes no espaço social da cidade. Por conseqüência, essas configuraçóes urbanas gerariam desigualdades educacionais (Flores, 2008; Kaztman \& Retamoso, 2008).

3 De acordo com estes modelos, os padrôes e normas de comportamento das pessoas tendem a ser moldadas por aqueles com quem mais tem contato e com quem mais frequentemente interagem. Partem do argumento do isolamento social de Wilson (1987), que defende que a concentraçáo da pobreza teria criado um ambiente social em desvantagem, uma vez que a pobreza do bairro desconecta as pessoas de relaçóes e interaçóes com a classe média.

4 Os modelos institucionais partem do pressuposto de que os indivíduos podem ser afetados pela qualidade dos serviços que são oferecidos em suas vizinhanças. No que diz respeito a desigualdades educacionais, as explicações oferecidas por esses modelos compreendem desde diferenças em termos de recursos e infraestrutura como em termos da capacidade de gestáo da escola).

5 Observamos diferentes formas de operacionalizar dimensóes das relaçóes sociais do bairro ou da vizinhanças, por exemplo: (i) porcentagem de famílias monoparentais em uma vizinhança como indicador de eficácia normativa (Ainsworth, 2002); (ii) porcentagem de famílias com alto status econômico, porcentagem de adultos que trabalham em ocupações de prestígio, nível de escolaridade da população adulta (para ilustrar mecanismos de socialização ou do isolamento da classe média e de seus modelos de papel social) (Duncan, 1994; Garner \& Raudenbush, 1991; Flores, 2008; Retamoso \& Kaztman, 2008); (iv) indicadores de segregação residencial, tais como o índice de dissimilaridade, de exposição, de Moran local, para medir a concentração da população de acordo com renda, escolaridade e/ou raça (indicadores para ilustrar mecanismos de isolamento da classe média e de seus modelos de papel social bem como para medir restriçáo de redes sociais) (Wilson, 2008; Flores, 2008). 
Os estudos acima descritos têm focalizado as desigualdades educacionais na escala intra-municipal, isto é, aquelas decorrentes dos fenômenos da segmentação e da segregação residencial que caracterizam a metrópole ${ }^{6}$. Entretanto raramente focalizam diferenças entre municípios, em especial entre municípios metropolitanos e não-metropolitanos, em termos de características mais globais dos municípios considerados como espaços institucionais, econômicos e sociais, tais como a natureza das políticas educacionais e da organização dos sistemas públicos de educação em cada município, a dinâmica econômica local, o grau de concentração territorial da pobreza, condições de habitação etc. Analisar nesta macro a relação entre a organização social do território e a reprodução das desigualdades educacionais torna-se fundamental em países como o Brasil, em razão da sua organização político-administrativa federativa, onde prevalece a autonomia municipal, da sua dimensão continental e das suas fortes assimetrias regionais. Este é o foco do presente estudo que parte da hipótese de um possível efeito metrópole sobre resultados escolares e tenta compreender que características dos contextos metropolitanos impedem o desenvolvimento da educação básica de qualidade.

O Observatório das Metrópoles ${ }^{7}$ tem realizado diversos estudos que constataram a existência nos grandes aglomerados urbanos dos efeitos concentrados da crise social decorrente da mudança do modelo de desenvolvimento (Ribeiro, 2004; 2007). Em resumo, trata-se da crise do regime dual de reprodução social que se instalou no Brasil, tornando vulneráveis pessoas, domicílios e grupos sociais. Os fundamentos desta crise são: (i) as transformações do mercado de trabalho por não assegurar de maneira estável os recursos necessários à reprodução social, seja pelo desemprego, ou subemprego ou ainda pela precariedade; (ii) as mudanças do âmbito familiar no sentido da sua fragilização como espaço de socialização e de redistribuição de recursos; (iii) os processos de segmentação e segregação residencial, cujas conseqüências são, de um lado, o isolamento sócio-territorial dos grupos vulnerabilizados - muitas vezes manifestada na estigmatização dos espaços onde estão concentrados - e de outro lado, a desorganização social no plano da família e da vida coletiva de bairro, o que tem implicado na destruição ou desvalorização do capital social ${ }^{8}$ forjado na sociabilidade que se constitui no âmbito das relaçóes de vizinhança; (iv) a crescente incorporação dos territórios populares à ordem mercantil que atinge não somente a moradia - tanto pela expansão da compra e venda, como pelo aluguel do imóvel -, mas todo o conjunto de economia local (gatonet, gaznet, gatoluz, segurança privatizada, etc.) que funciona sob bases institucionais paralelas às hegemônicas na sociedade, difundindo valores de um individualismo hobbesiano e gerando a instabilidade nas relaçóes sociais; e, por último (v) a tendência à reprodução do habitat urbano precário, o que pode ser expresso nos seguintes dados estilizados: no Rio de Janeiro e em Belo Horizonte estima-se que cerca de $20 \%$ da população morem em favelas; em São Paulo, metrópole mais dinâmica do país, dados de 2000 registraram um total de 241 mil domicílios em favela, concentrando

6 Estudos para compreender as diferenças intra-metropolitanas já foram realizados pelos autores, tomando como foco a cidade do Rio de Janeiro. Ver Ribeiro \& Koslinski, 2009.

7 Informaçôes mais detalhadas sobre os trabalhos realizados por esse grupo de pesquisa estão no site: http:// web.observatoriodasmetropoles.net.

8 Fazemos aqui alusão ao conceito de capital social formulado por Pierre Bourdieu (1997), definido essencialmente como o conjunto de relaçóes sociais que dispóe um indivíduo ou coletividade através das quais circulam várias formas de recursos. 
cerca de 1 milhão de favelados, entretanto, estatísticas mais refinadas apontam, apenas na cidade de Sáo Paulo, 1,2 milhóes de favelados, 11\% da populaçáo municipal.

Esse conjunto de transformaçôes do "regime de bem-estar social" constitui o fundo sóciocultural que associa urbanização e a expansão da violência, especialmente a traduzida nos homicídios. Há 20 anos, a violência nas grandes cidades tinha outra dimensão. Os dados sobre a criminalidade violenta nas metrópoles brasileiras são tão impressionantes que levaram o historiador Luiz Mir (2004) a cunhar a expressão metrópoles da morte: a taxa de homicídios dobrou em vinte anos; a média da taxa de vítimas de homicídio por 100 mil habitantes entre as regióes metropolitanas, entre 1998 e 2002, foi de 46,7 vítimas por 100 mil habitantes. Esse valor está bem acima da média da taxa nacional de vítimas de homicídio, que nesse mesmo período foi de 28,6 vítimas por 100 mil habitantes. Ou seja, a incidência de homicídios nas regiôes metropolitanas é quase duas vezes maior que a incidência nacional. Como é conhecido, as vítimas de homicídio concentram-se nos jovens do sexo masculino, como vêm mostrando vários estudos. A associação entre a violência letal e a metropolização parece, portanto, apresentar variadas evidências em estudos empíricos realizados por especialistas.

É importante frisar que a relação entre a metropolização e a criminalidade violenta deve ser compreendida no quadro de ruptura do sistema de reciprocidade (Velho, 1996), baseada na mencionada matriz sócio-cultural híbrida ${ }^{10}$ que serviu de amortecedora dos conflitos inerentes ao caráter conservador da nossa modernização. Nas metrópoles brasileiras, com efeito, experimentam-se na vida cotidiana os efeitos da díade contraditória decorrente da aceleração da difusão de expectativas igualitárias (pela escola, pelo mercado, pela política, pela religião), perdendo pouco a pouco legitimidade o lado hierárquico da sociedade, ao mesmo tempo em que a economia, as instituiçóes e o território excluem, desigualam e segregam,com enorme potencial corrosivo da crença de estar toda a população na mesma sociedade, compartilhando o mesmo projeto de futuro. Este descompasso foi perfeitamente percebido por Peralva, (2000) ao evidenciar a paradoxal simultaneidade entre os processos de democratizaçáo, integraçáo sócio-cultural e a exacerbação da violência.

Ao mesmo tempo, a reconfiguração social das altas classes médias, a construção da percepção coletiva de declínio e perda de prestígio, a difusão da "cultura do medo" (Soares, 1996) criam justificativas para a des-responsabilização social dos "patrôes" com relação às trocas de proteção, recursos, benefícios a que eram obrigados como contrapartida da submissão. Soares (1997) retira duas conseqüências destas mudanças em termos de comportamentos prováveis das classes populares com base na leitura desta ordem que, de híbrida, tornou-se dual: de um lado, a passividade decorrente da crença que a pobreza, o desamparo, a precariedade, resultam

9 Sobre a definição e características predominantes em distintos regimes de bem-estar ver Esping Andersen, (1999) Social Foundations of Post Industrial Economies. Oxford, Oxford University Press. O conceito de regime dual de bem-estar social foi proposta por Filgueiras (1988).

10 Estamos nos referindo a interpretação da duplicidade do processo de modernização cultural brasileiro que combinou valores hierárquicos e igualitários, impessoalismo e personalistas, individualismo e personalismo. Ver como exemplo desta interpretação e, sobretudo, seu efeito nos padróes de interação social na sociedade moderna brasileira Datta $(1981,1991)$ e Soares (1997). Para uma visão crítica dessa interpretação ver Souza(200). 
da incapacidade dos próprios pobres em enfrentar as novas condiçóes sociais; de outro lado, "a hierarquia sem nenhum tipo de mutualidade tradicional é reduzida ou pode ser entendida pela classe baixa, como reduzida à sua estrutura vertical formal” (Soares, 1997, p. 232). Ou seja, a dualidade pode estar sendo interpretada como um incentivo ao individualismo hobbesiano, onde o uso da força parece ser o caminho para obter os recursos, os benefícios, a proteção e a honra.

Por outras palavras, nas metrópoles brasileiras enfrenta-se a face mais aguda dos desafios de uma sociedade que consolida a democracia e homogeneíza seus valores e crenças republicanas - processo fortemente correlacionado com a universalização do ensino básico - mas, ao mesmo tempo, mantém e aumenta as desigualdades sociais. Simultaneamente, nelas se multiplicam as demandas urgentes na área de saneamento ambiental, moradia, pavimentação, necessidades sociais com maior capacidade de agenciar o sistema político em razão da sua visibilidade social, concorrendo com as prementes urgências de elevação do nível educativo da população frente aos imperativos do novo modelo de desenvolvimento, mas com pouca capacidade de geração de rendimentos políticos no curto prazo. É conhecido o drama das políticas públicas nas grandes cidades decorrente da lógica política funcionando segundo o padrão do localista e de curto prazo, atendendo à demanda dos "votos com os pés”, e a imperiosa necessidade da provisão de bens públicos dotados de elevadas doses de efeitos de economia externa, atendendo no longo prazo e de maneira difusa ao conjunto da população.

Dada esta realidade, partimos do pressuposto de que esses contextos urbanos metropolitanos conformam condiçóes menos adequadas em termos da oferta de bem-estar social e, por conseqüência, apresentam menor capacidade de garantir a oferta de educaçáo fundamental de qualidade.

\section{A pesquisa: dados, variáveis e os modelos}

Para ilustrar um possível efeito-metrópole sobre oportunidades educacionais, primeiramente, realizamos análises que nos permitiram observar as diferenças de resultados escolares de municípios que integram as regióes metropolitanas e aqueles fora da dinâmica metropolitana. Em seguida, realizamos análises que nos permitiram explorar dimensóes que poderiam explicar o efeito-metrópole sobre oportunidades educacionais. As análises apresentadas focalizam resultados no ensino fundamental e foram realizadas a partir da compilação de dados agregados no nível dos municípios a partir de diversas bases de dados (Prova Brasil 2005, Censo Escolar 2005, DATASUS, diversos anos, PNUD e do Censo IBGE 2000).

Antes de explicar mais detalhadamente o modelo utilizado nas análises, uma breve explicação sobre a organização do sistema educacional brasileiro se faz necessário. A partir da nova Lei de Diretrizes e Bases da Educação Nacional (Lei 9394 de 1996), o ensino básico passou a compreender a educação infantil, ensino fundamental e o ensino médio. $\mathrm{O}$ ensino fundamental obrigatório iniciava-se aos 7 anos de idade e compreendia 8 anos, da $1^{\text {a }}$ a $8^{\text {a }}$ séries. Recentemente (Lei 11274/2006) o ensino fundamental foi estendido para 9 anos, iniciando-se aos 6 anos de idade e passa a compreender do $1^{\circ}$ ao $9^{\circ}$ ano. 
A Lei 9394/96 também trata da organização da educação nacional e da divisão das incumbências entre os entes federados. Vale ressaltar que a partir da constituição de 1988, os municípios passaram a ser reconhecidos como entes federativos. Ou seja "os municípios podem suplementar a legislação federal e a estadual no que couber .... podem organizar seu sistema de ensino" (Cury, 2006, p.49). O ensino fundamental passa a ser foco prioritário do poder público municipal. Os Estados ficam responsáveis por organizar e definir formas de colaboração com os municípios para a oferta do ensino fundamental. Entretanto observamos nas últimas décadas a proliferação de iniciativas, em especial do governo federal, que fomentaram a descentralização das matrículas do ensino fundamental dos estados em direção aos municípios (Koslinski, 2000). De acordo com dados oficiais, em 2005 as matrículas do ensino fundamental no Brasil estavam divididas da seguinte forma: $53,6 \%$ rede pública municipal, $36,2 \%$ rede pública estadual, $0,1 \%$ rede pública federal e $10,1 \%$ rede privada (INEP - Censo Escolar, 2005). Assim, apesar de haver grande variação em termos de municipalização das matrículas do ensino fundamental nos diferentes estados da federação, optamos por tratar os dados referentes aos resultados escolares agregados no nível dos municípios.

Para a realização da comparação entre municípios que integram e aqueles que não integram a dinâmica metropolitana, consideramos somente municípios com mais de 50.000 habitantes, localizados nos estados que contém os 15 Grandes Aglomerados Urbanos- GEUB's que, de acordo com uma análise realizada pelo "Observatório das Metrópoles”, exercem funçóes metropolitanas ${ }^{11}$ : São Paulo, Rio de Janeiro, Belo Horizonte, Porto Alegre, Brasília, Curitiba, Salvador, Recife, Fortaleza, Campinas, Manaus, Vitória, Goiânia, Belém, Florianópolis. Assim, foram considerados para esta análise municípios que integram a dinâmica metropolitana. No total foram estudados 483 municípios $^{12}: 138$ considerados integrados à dinâmica metropolitana e 345 não integrados a essa dinâmica.

Para tratar das oportunidades educacionais, foram utilizados dados da Prova Brasil $2005^{13}$ (INEP/MEC) agregados no nível do município. Mais especificamente, o trabalho utiliza

11 Os Grandes Espaços Urbanos foram considerados aqueles que concentram as atividades de articulação e coordenaçáo da economia, próprias da metrópole nesta fase do desenvolvimento econômico. Por razóes da utilização de critérios imprecisos na definição das fronteiras das regióes metropolitanas consideramos para fins desse trabalho apenas os municípios pólo e aqueles que apresentaram indicadores de real integração à dinâmica das aglomerações urbanas metropolitanas. Sobre a metodologia e os resultados deste trabalho ver Moura, Delgado, Deschamps et al (2007).

12 De acordo com dados do IBGE, são 5.564 municípios no total. .

13 O Sistema de Avaliação da Educação Básica (SAEB) foi a primeira iniciativa brasileira de avaliação da educação básica em escala nacional. Foi desenvolvido no final da década de 80, aplicado pela primeira vez em 1990 e em 1995, devido a uma reestruturação metodológica, torna-se possível a comparação entre os desempenhos educacionais ao longo dos anos. Tem caráter amostral e avalia alunos de $4^{\mathrm{a}}$ e $8^{\mathrm{a}}$ séries do ensino fundamental e do $3^{\circ}$ ano do ensino médio, em escolas públicas e privadas, localizadas em áreas urbanas e rurais. O Prova Brasil é um sistema de avaliação nos moldes do SAEB, entretanto tem base censitária e somente focaliza as escolas públicas urbanas. Foi criado a partir da necessidade de tornar a avaliaçáo mais detalhada; por ser censitário oferece resultados para os municípios e para as escolas públicas urbanas. Realizado a cada dois anos, em sua primeira edição (2005) considerou as escolas que matricularam pelo menos 30 alunos nas séries avaliadas (4a série e $8^{\mathrm{a}}$ série do ensino fundamental). $\mathrm{O}$ ensino fundamental é dividido em 2 segmentos e foram avaliadas a última série do primeiro segmento ( $4^{\mathrm{a}}$ serie) e última série do segundo segmento ( $8^{\mathrm{a}}$ série). A idade própria para o atendimento da $4^{\mathrm{a}}$ é de 
o Índice de Desenvolvimento para a Educação Básica (IDEB) das regiôes urbanas de cada município para o ano de 2005. Este índice foi criado pelo Ministério da Educação em 2007 como parte do Plano de Desenvolvimento da Educaçáo Básica. Ele engloba tanto dados sobre aprovação escolar como as médias de desempenho em testes padronizados de proficiência em Português e em Matemática. Sua concepção partiu da idéia de que um índice de qualidade dos sistemas escolares e das escolas precisaria conjugar tanto indicadores de fluxo escolar como de aprendizagem ${ }^{14}$.

Este trabalho utilizou o IDEB municipal - total urbano de $1^{\text {a }}$ fase, que conjuga a taxa de aprovação até a quarta série e os resultados da Prova Brasil para a $4^{a}$ série e o IDEB municipal - total urbano de $2^{a}$ fase, que conjuga a taxa de aprovaçáo de $5^{a}$ à $8^{a}$ séries e os resultados da Prova Brasil para a $8^{\mathrm{a}}$ série. A escala do IDEB vai de 0 a 10 pontos.

Para explorar as hipóteses sobre que dimensóes poderiam explicar o efeito-metrópole sobre as oportunidades educacionais, foram utilizadas variáveis relacionadas aos seguintes aspectos dos municípios:

(i) Condiçóes sócio-econômicas: PIB municipal per capita e renda pessoal per capita;

(ii) Condiçóes sócio-urbanas;

(iii) Contexto Social: taxa de homicídios por 100 mil habitantes); e;

(iv) Políticas educacionais (taxa de municipalização do ensino fundamental e de atendimento à pré-escola).

Este último conjunto de indicadores parte do pressuposto de que a qualidade da educaçáo oferecida em cada município é influenciada não somente pelas condiçóes socioeconômicas dos municípios e pelo possível impacto da crise de sociabilidade característicos das metrópoles, como também das políticas educacionais por eles oferecidas. A municipalização do ensino fundamental poderia significar melhoria no provimento deste serviço público devido à maior proximidade entre os órgãos governamentais e os atores relevantes (pais de alunos, professores e diretores das escolas). Esta melhoria também seria possibilitada pelo fato de que a transferência de vagas do ensino fundamental para o município é seguida por maior aporte de recursos devido à lógica do funcionamento do FUNDEF ${ }^{15}$ (Koslinski, 2000). No que diz respeito ao atendimento a pré-escola ${ }^{16}$, pesquisas internacionais mostram a freqüência que

10 anos e para o atendimento da $8^{\text {a }}$ série é 14 anos.

14 “...sua proposta é de que o Índice de Desenvolvimento Educacional considere tanto informaçóes de desempenho em exames padronizados como as de fluxo escolar, tendo como resultado a combinaçáo de dois outros indicadores - a) pontuação média dos estudantes em exames padronizados ao final de determinada etapa da educaçáo básica ( $4^{\mathrm{a}}$ e $8^{\mathrm{a}}$ séries do ensino fundamental...) e b) taxa média de aprovação dos estudantes da correspondente etapa de ensino -, seja de fácil compreensão, simples de calcular, aplicável às escolas e explícito em relação à "taxa de troca” entre probabilidade de aprovação e proficiência dos estudantes.” (Fernandes, 2007, p.5).

15 A Lei 9394/96 atribui aos Municípios a função de oferecer a educação infantil e, com prioridade, o ensino fundamental. O FUNDEF reforça esta prioridade ao redistribuir recursos vinculados à educação entre Estados e Municípios de acordo com o número de matrículas que cada um oferece no ensino fundamental.

16 A partir do Lei 9394/96, a educação infantil passa a fazer parte da educação básica, mesmo que não faça parte do ensino obrigatório. 
este nível de ensino exerce impacto tanto nas condições de vida das famílias quanto sobre as oportunidades de escolarização das crianças. De um lado, possibilita aos pais, especialmente as mães, deixarem as crianças sob cuidados mínimos enquanto trabalham. De outro, oferece oportunidades de socialização e de desenvolvimento de habilidades cognitivas e não cognitivas (atenção e disciplina) necessárias para preparação e diminuição das desigualdades entre alunos que ingressam no Ensino Fundamental (Alves, 2007). Por tanto, a maior abrangência no atendimento à pré-escola implicaria em maiores oportunidades educacionais oferecidas pelos municípios.

O Quadro 1 e 2 mostram uma breve descrição das variáveis utilizadas nas análises e suas estatísticas descritivas, respectivamente.

\section{QUADRO 1. VARIÁVEIS UTILIZADA}

\begin{tabular}{|c|c|c|c|}
\hline \multicolumn{2}{|r|}{ Variáveis } & Tipo & \multirow[b]{2}{*}{$\begin{array}{l}\text { Descrição } \\
\text { Í́ndice de desenvolvimento da Educação Básica - IDEB - } \\
\text { calculado a partir de dados sobre aprovação escolar até a 4a } \\
\text { série e do desempenho da Prova Brasil, para escolas nas } \\
\text { regiões urbanas no ano de } 2005 \text {. }\end{array}$} \\
\hline 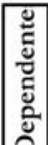 & IDEB total urbano 1a fase & Contínua & \\
\hline : & IDEB total urbano $2 \mathrm{a}$ fase & Continua & $\begin{array}{l}\text { Índice de desenvolvimento da Educação Básica - IDEB - } \\
\text { calculado a partir de dados sobre aprovação escolar de 5a a 8a } \\
\text { séries e do desempenho da Prova Brasil, para escolas nas } \\
\text { regiões urbanas no ano de } 2005 \text {. }\end{array}$ \\
\hline \multirow{8}{*}{ 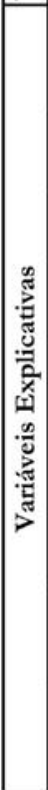 } & $\begin{array}{l}\text { Integração à dinâmica } \\
\text { metropolitana }\end{array}$ & Dicotômica & $\begin{array}{l}\text { Valor } 1 \text { para os municípios que integram os } 15 \text { aglomerados } \\
\text { urbanos que exercem funções metropolitanas, } 0 \text { para os } \\
\text { demais municípios. }\end{array}$ \\
\hline & Regiões Norte e Nordeste & Dicotômica & $\begin{array}{l}\text { Valor } 1 \text { para municípios localizados nas Regiões Norte e } \\
\text { Nordeste valor } 0 \text { para os municípios localizados nas demais }\end{array}$ \\
\hline & PIB per Capita & Contínua & $\begin{array}{l}\text { PIB per capita dos municípios calculado a partir de dados do } \\
\text { IBGE } 2000 \text {. }\end{array}$ \\
\hline & Renda per Capita & Continua & $\begin{array}{l}\text { Renda per capita dos municípios retirado do Atlas do } \\
\text { Desenvolvimento Humano - PUND 2000) }\end{array}$ \\
\hline & Índice de Condição Social & Contínua & $\begin{array}{l}\text { Índice composto pelo Índice de Carência Habitacional (\% de } \\
\text { domicílios com coleta de lixo, saneamento e abastecimento de } \\
\text { água inadequados -desenvolvido a partir de dados do Censo } \\
2000 \text { ) e da taxa de Pobreza (\% de domicilios com renda } \\
\text { inferior a R\$75,00 - PNUD 2000) }\end{array}$ \\
\hline & $\begin{array}{l}\text { Taxa de homicídio por } \\
100.000 \text { hab }\end{array}$ & Contínua & $\begin{array}{l}\text { Taxa de vítimas de homicídio por } 100.000 \text { habitantes calcula a } \\
\text { partir de dados do DATASUS } 2002\end{array}$ \\
\hline & $\begin{array}{l}\text { Municipalização do Ensino } \\
\text { Fundamental }\end{array}$ & Contínua & $\begin{array}{l}\% \text { de vagas no ensino fundamental público oferecidas pelo } \\
\text { município calculada a partir de dados do Censo Escolar } 2005\end{array}$ \\
\hline & Atendimento à pré-escola & Contínua & $\begin{array}{l}\text { Média do atendimento à pré-escola entre } 2000 \text { e } 2005 \\
\text { calculada a partir da relação entre o número de crianças de } 4 \text { a } \\
5 \text { anos nos municípios (DATASUS) e o número de matrículas }\end{array}$ \\
\hline
\end{tabular}




\section{QUADRO 2. ESTADÍSTICAS DESCRITIVAS DAS}

VARIÁVEIS UTILIZADAS

\begin{tabular}{|l|c|c|}
\hline \multicolumn{1}{l}{ Variáveis } & Média & \multicolumn{1}{c}{ Dp } \\
\hline IDEB total urbano - 1a fase & 4,08 & 0,75 \\
\hline IDEB total urbano - 2a fase & 3,57 & 0,61 \\
\hline PIB per capita & 696,38 & 695,4 \\
\hline Renda per capita & 279 & 130,7 \\
\hline Índice de Condição Social & 0,75 & 0,19 \\
\hline Taxa de homicídio por 100.000 hab & 30,95 & 31,88 \\
\hline Municipalização do Ensino Fundamental & 56,72 & 22,43 \\
\hline Atendimento à pré-escola & 0,54 & 0,29 \\
\hline
\end{tabular}

Além da apresentação de algumas estatísticas descritivas, utilizamos as variáveis acima apresentadas em regressóes lineares para estimar o efeito das variáveis relacionadas às condiçóes sócioeconômicas, à tensão social e às políticas educacionais sobre os IDEBs urbanos de $1^{\text {a }}$ fase e de $2^{\text {a }}$ fase dos municípios. Para tanto, foram utilizados modelos em passos sucessivos, nos quais novas variáveis vão sendo acrescentadas aos modelos anteriores, para observar quais variáveis independentes consideradas fazem parte da explicação do efeito-metrópole. Realizamos estas análises para o conjunto dos municípios acima descritos, bem como para um conjunto mais restrito que inclui somente municípios pertencentes às regióes Sul, Sudeste e Centro-Oeste.

\subsection{Resultados descritivos}

Para explorar o que chamamos de efeito-metrópole sobre oportunidades educacionais, observamos as diferentes médias dos IDEBs de municípios integrados e aqueles não integrados às regióes metropolitanas nas diferentes regióes e estados brasileiros.

Os gráficos 1 e 2 mostram estas diferenças para o IDEB urbano de $1^{\text {a }}$ fase: 
GRÁFICO 1. IDEB 2005 - TOTAL URBANO 1ª FASE - MUNICÍPIOS METROPOLITANOS E NÃO METROPOLITANOS POR REGIÃO

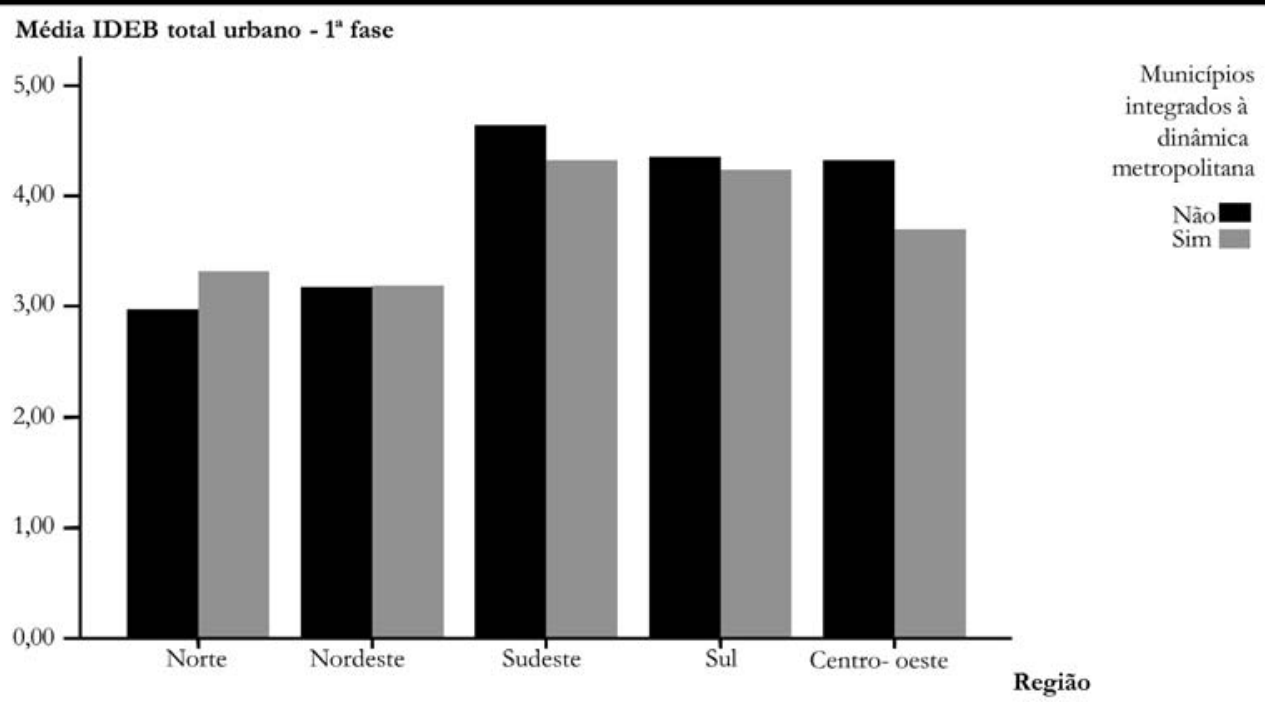

GRÁFICO 2. IDEB 2005 - TOTAL URBANO 1ªASE - MUNICÍPIOS METROPOLITANOS E NÃO METROPOLITANOS POR UF

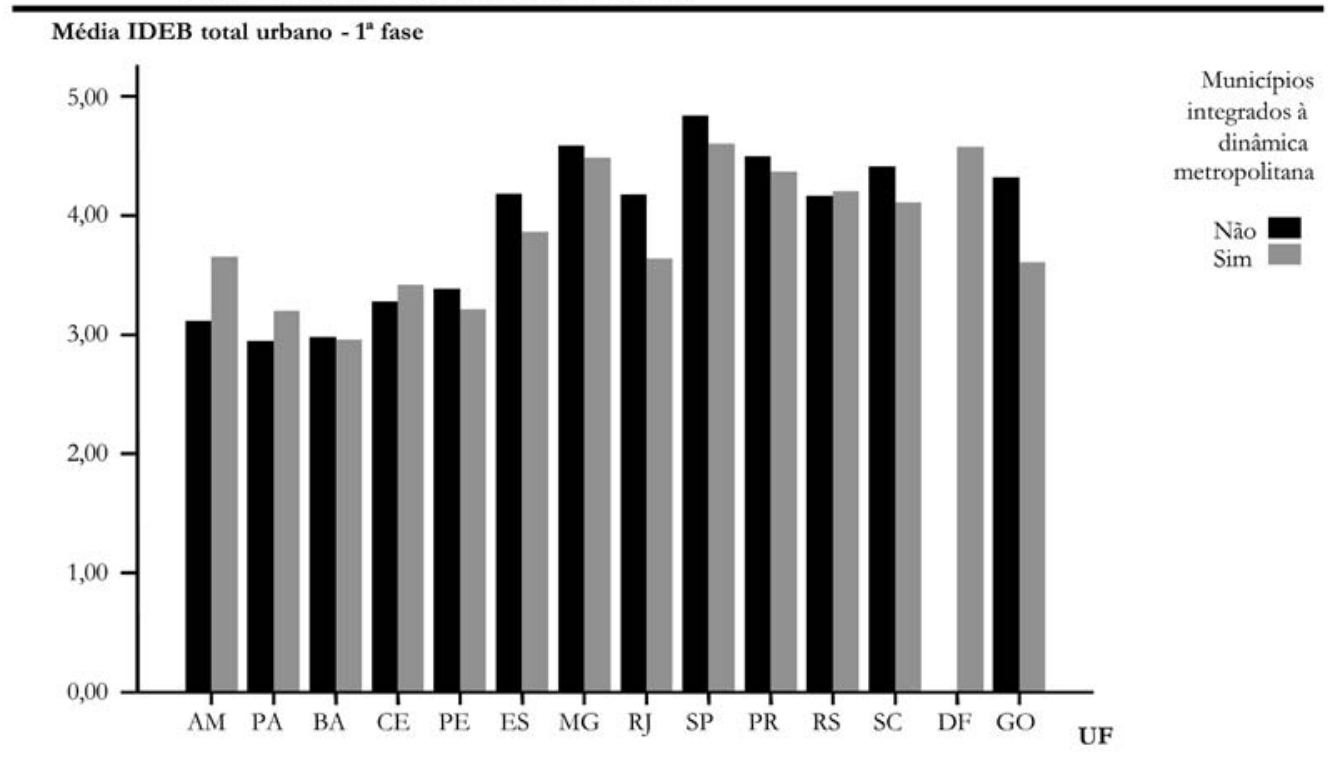

Em primeiro lugar, podemos observar nos gráficos 1 e 2 que a média do IDEB para os municípios metropolitanos e não-metropolitanos nas 5 regióes do país é bastante baixo, não chegando em nenhum caso a 5 pontos. Os gráficos também evidenciam as grandes diferenças regionais, se comparamos os resultados das regióes Norte e Nordeste com as demais regióes.

No que diz respeito ao foco deste estudo, observamos que a média do IDEB urbano de $1^{\text {a }}$ fase para os municípios metropolitanos nas regióes Sul, Sudeste e Centro-Oeste é mais baixa do que a média para os municípios fora das regióes metropolitanas. Parece não haver diferença 
entre estas médias na região Nordeste, e a relação se inverte nos municípios da Região Norte: os municípios metropolitanos apresentam maior desempenho educacional se comparados com os municípios não-metropolitanos.

No gráfico 2, observamos que as diferenças do IDEB entre municípios metropolitanos e nãometropolitanos são mais acentuadas nos seguintes estados: Espírito Santo, Rio de Janeiro, São Paulo, Santa Catarina e Goiás. Ou seja, nestes estados, o efeito-metrópole estaria exercendo um impacto mais acentuado.

Os gráficos 3 e 4 ilustram resultados similares aos anteriores levando em conta os resultados dos municípios no IDEB urbano de $2^{a}$ fase, que mede a taxa de aprovação de $5^{\mathrm{a}}$ à $8^{\mathrm{a}}$ série e os resultados do Prova Brasil para a $8^{\mathrm{a}}$ série:

\section{GRÁFICO 3. IDEB 2005 - TOTAL URBANO 2a FASE - MUNICÍPIOS METROPOLITANOS} E NÃO METROPOLITANOS POR REGIÃO

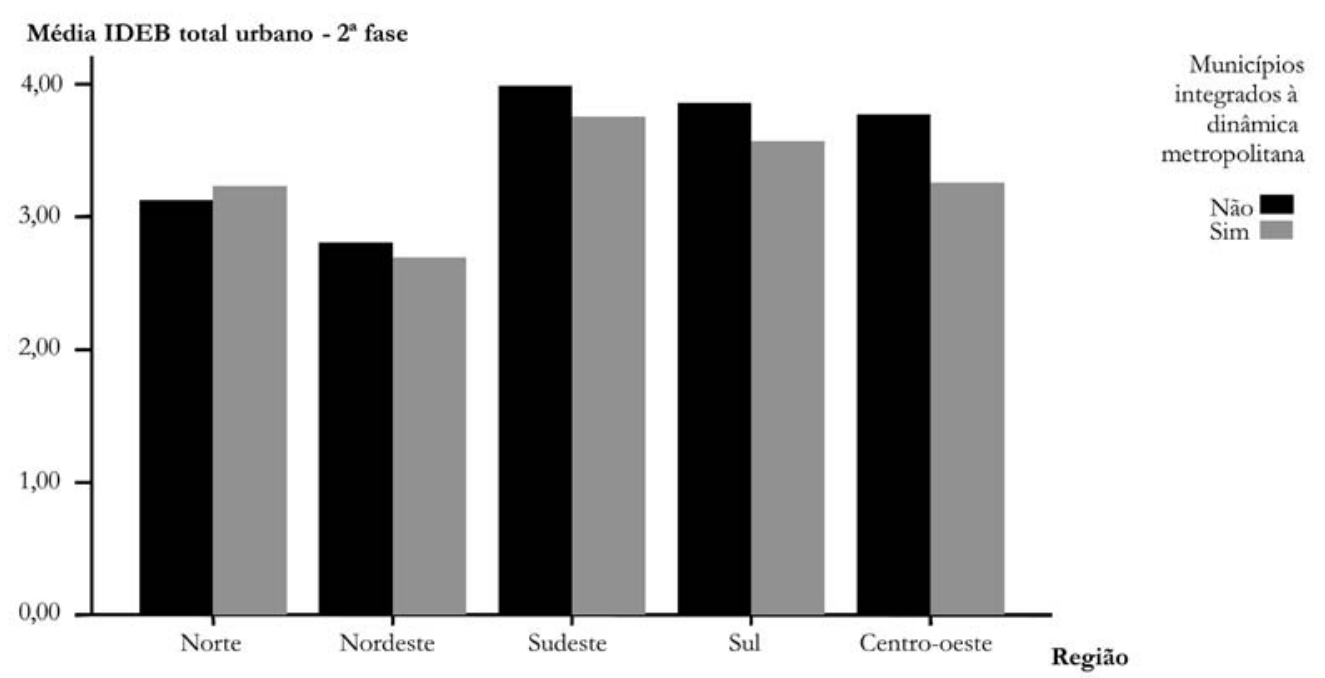




\section{GRÁFICO 4. IDEB 2005 - TOTAL URBANO $1^{\mathrm{a}}$ FASE - MUNICÍPIOS METROPOLITANOS E NÃO METROPOLITANOS POR UF}

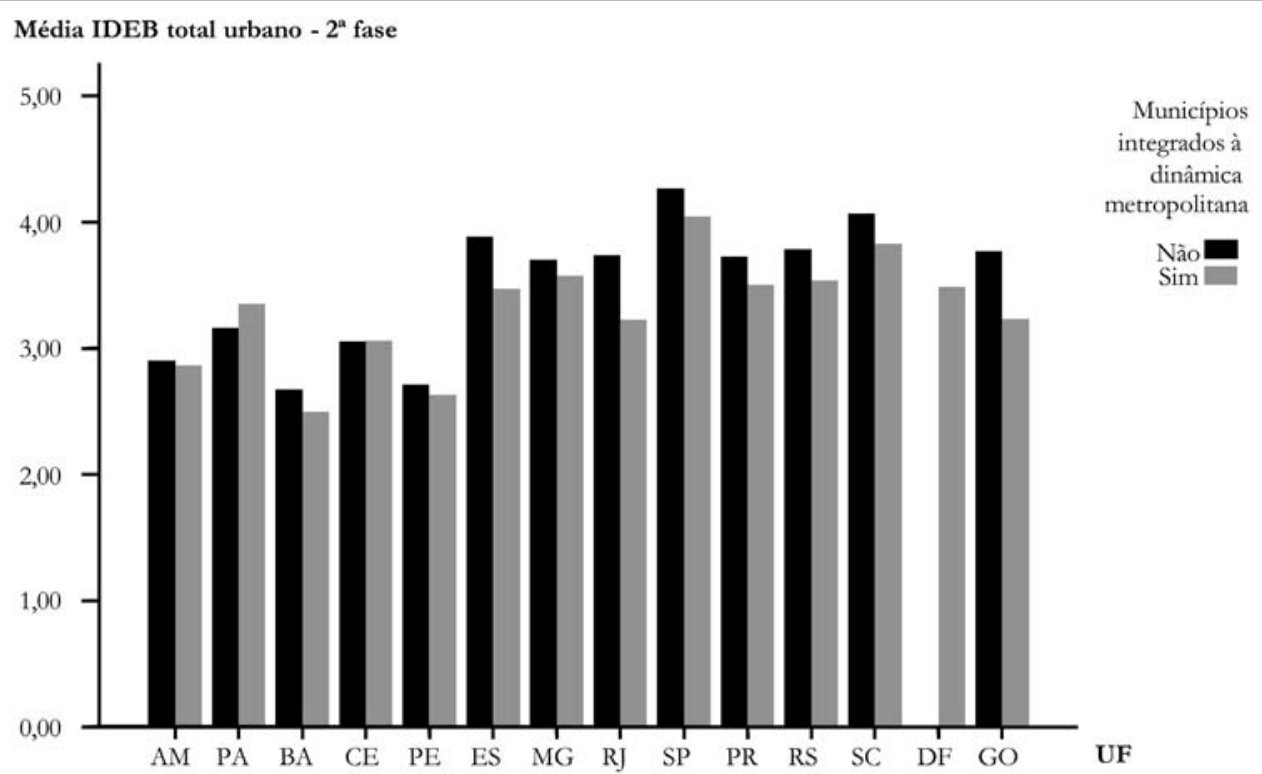

Observamos, neste caso, um menor IDEB para municípios integrados à dinâmica metropolitana não somente nas regióes Sul, Sudeste e Centro-Oeste como também na região Nordeste. Isto é, o efeito-metrópole se estende para essa região do país. Mais ainda, mesmo que em alguns estados esta tendência se mostre pouco acentuada, observamos que se trata de uma tendência em todos os estados estudados, com exceção do Estado do Pará.

Frente às tendências acima observadas, esse trabalho, na sessão seguinte, explora algumas explicaçóes para a qualidade da educação nos municípios que incluem a questão social das metrópoles.

\subsection{Resultados dos Modelos}

Antes de observar as regressóes estimando os IDEBs de $1^{\text {a }}$ fase e de $2^{\text {a }}$ fase dos municípios, observamos as diferenças entre os municípios que integram e os que não integram a dinâmica metropolitana, no que diz respeito aos indicadores de condições sócio-econômicas, de tensão social e de políticas educacionais acima mencionados. 
QUADRO 3. MÉDIAS DAS VARIÁVEIS INDEPENDENTES POR REGIÃO E INTEGRAÇÃO À DINÂMICA METROPOLITANA

\begin{tabular}{|c|c|c|c|c|c|c|c|c|}
\hline REGIÃO & $\begin{array}{r}\text { Integ } \\
\text { dinâ } \\
\text { Metro }\end{array}$ & $\begin{array}{l}\text { ção à } \\
\text { hica } \\
\text { litana }\end{array}$ & $\begin{array}{l}\text { PIB per } \\
\text { capita }\end{array}$ & $\begin{array}{l}\text { Renda per } \\
\text { capita }\end{array}$ & $\begin{array}{c}\text { Îndice de } \\
\text { Condição } \\
\text { Social }\end{array}$ & $\begin{array}{c}\text { Taxa de } \\
\text { homicídio } \\
100.000 \text { hab }\end{array}$ & $\begin{array}{c}\text { Municipaliz. } \\
\text { Ensino } \\
\text { Fundamental }\end{array}$ & $\begin{array}{l}\text { Atendimento } \\
\text { à pré-escola }\end{array}$ \\
\hline \multirow{4}{*}{ Norte } & \multirow[t]{2}{*}{ Nào } & Média & 361,99 & 132,66 & 0,41 & 24,02 & 81,36 & 0,51 \\
\hline & & DP & 380,98 & 49,04 & 0,12 & 29,56 & 24,71 & 0,28 \\
\hline & \multirow[t]{2}{*}{ Sim } & Média & 486,78 & 222,72 & 0,68 & 23,25 & 52,07 & 0,32 \\
\hline & & DP & 432,87 & 82,3 & 0,12 & 8,55 & 33,83 & 0,1 \\
\hline \multirow{4}{*}{ Nordeste } & \multirow[t]{2}{*}{ Não } & Média & 246,79 & 132,17 & 0,5 & 23,17 & 75,48 & 0,45 \\
\hline & & DP & 111,8 & 41,68 & 0,14 & 20,67 & 15,74 & 0,22 \\
\hline & \multirow[t]{2}{*}{ Sim } & Média & 841,05 & 182,96 & 0,63 & 38,95 & 71,96 & 0,38 \\
\hline & & DP & 932,56 & 87,74 & 0,11 & 25,24 & 20,39 & 0,23 \\
\hline \multirow{4}{*}{ Sudeste } & \multirow[t]{2}{*}{ Não } & Média & 812,21 & 335,24 & 0,86 & 28,7 & 47,5 & 0,69 \\
\hline & & DP & 662,93 & 84,53 & 0,09 & 32,33 & 18,9 & 0,29 \\
\hline & \multirow[t]{2}{*}{ Sim } & Média & 983,59 & 342,39 & 0,85 & 61,76 & 49,02 & 0,55 \\
\hline & & DP & 1107,63 & 161,66 & 0,08 & 39,57 & 24,73 & 0,37 \\
\hline \multirow{4}{*}{ Sul } & \multirow[t]{2}{*}{ Não } & Média & 735,03 & 329,38 & 0,83 & 16,46 & 49,96 & 0,5 \\
\hline & & DP & 313,02 & 79,9 & 0,07 & 13,1 & 12,04 & 0,15 \\
\hline & \multirow[t]{2}{*}{ Sim } & Média & 906,33 & 339,35 & 0,89 & 22,64 & 53,3 & 0,37 \\
\hline & & DP & 693,34 & 134,02 & 0,05 & 11,66 & 13,43 & 0,15 \\
\hline \multirow{4}{*}{ Centro-Oeste } & \multirow[t]{2}{*}{ Não } & Média & 558,09 & 289,58 & 0,77 & 20,24 & 54,93 & 0,32 \\
\hline & & DP & 250,37 & 50,53 & 0,07 & 9,39 & 11,26 & 0,21 \\
\hline & \multirow[t]{2}{*}{ Sim } & Média & 412,02 & 253,64 & 0,68 & 33,8 & 59,9 & 0,19 \\
\hline & & DP & 399,41 & 156,41 & 0,13 & 9,93 & 18,28 & 0,14 \\
\hline \multirow{4}{*}{ TOTAL } & \multirow[t]{2}{*}{ Nào } & Média & 620,84 & 268,28 & 0,73 & 24,26 & 57,65 & 0,57 \\
\hline & & DP & 540,8 & 117,91 & 0,2 & 26,43 & 22,07 & 0,27 \\
\hline & \multirow[t]{2}{*}{ Sim } & Média & 885,23 & 305,81 & 0,8 & 46,95 & 54,42 & 0,45 \\
\hline & & DP & 957,46 & 155,48 & 0,13 & 37,74 & 23,23 & 0,32 \\
\hline
\end{tabular}

No quadro 3, chamamos especial atenção para as tendências observadas no que se refere às variáveis taxa de homicídios por 100.000 habitantes e atendimento à pré-escola. Observamos que a média da taxa de homicídio é mais elevada nos municípios metropolitanos do que nos municípios não metropolitanos nas regiōes Nordeste, Sudeste, Sul e Centro-Oeste, sendo esta diferença bastante acentuada na Região Sudeste. No que diz respeito ao atendimento à préescola, em todas as regióes, observamos que os municípios metropolitanos apresentam menor cobertura deste nível de ensino se comparados com os municípios não metropolitanos.

Também é importante a constatação de que a média do índice de condição social é marcadamente menor para os municípios metropolitanos na região Centro-Oeste e ligeiramente menor na região Sudeste (nos Estados de São Paulo, Rio de Janeiro e Minas Gerais). Essa variável qualifica a partir de medidas de taxa de pobreza e de carência habitacional, a condição socioeconômica tal qual experimentada pela população residente nos aglomerados urbanos com funçóes metropolitanas nessas regióes. Por outro lado, o PIB per capita e a renda per capita tendem a ser, em média, mais altos nos municípios integrados à dinâmica metropolitana em todas as regiôes, com exceção da Região Centro-Oeste.

Na quadro 4 observamos os resultados para os modelos estimando IDEB 2005 - total urbano $1^{\text {a }}$ fase. São apresentados 5 modelos nos quais as variáveis explicativas anteriormente descritas foram progressivamente incluídas. 
QUADRO 4. REGRESSÕES LINEARES ESTIMANDO IDEB 2005 - TOTAL URBANO $1^{\text {a }}$ FASE

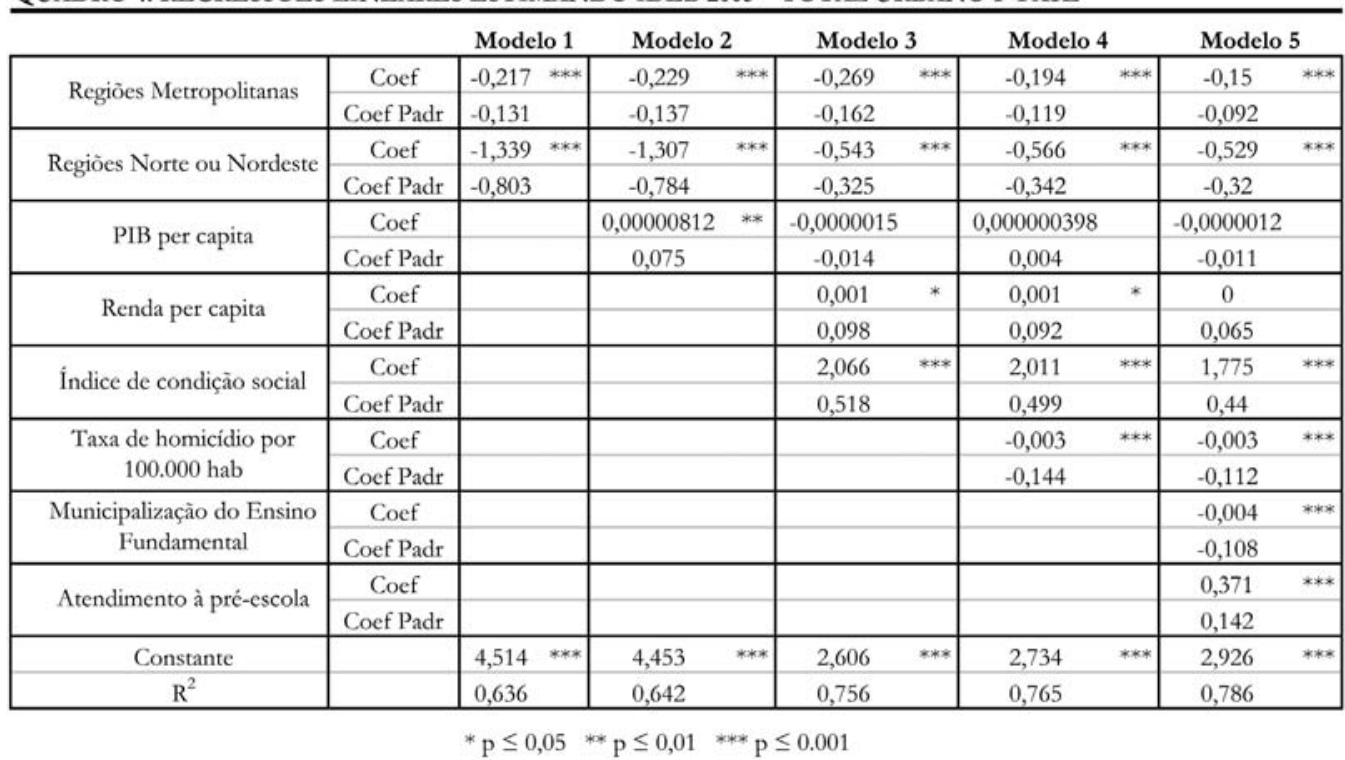

No quadro 4 - modelo 1, foram introduzidas somente as variáveis dicotômicas "integração à dinâmica metropolitana" e "regióes Norte e Nordeste". Observamos que ambas as variáveis exercem um impacto negativo sobre o desempenho educacional dos municípios. As discrepâncias regionais são marcantes: estima-se que pertencer às regióes Norte ou Nordeste diminui, em média, 1,34 o IDEB urbano de $1^{\text {a }}$ fase dos municípios. Mas, além dessas grandes diferenças regionais, observamos um efeito estatísticamente significativo, mesmo que moderado, da integração na dinâmica metropolitana: a integração a essa dinâmica é acompanhada por um decréscimo em torno de 0,22 no IDEB urbano de $1^{\text {a }}$ fase dos municípios.

O PIB per capita dos municípios é introduzido a partir do modelo 2. Apesar desta variável apresentar um efeito estatísticamente significativo nesse modelo, ela não se mantém robusta nos modelos seguintes em que são introduzidos outros controles. $\mathrm{O}$ mesmo ocorre com a variável renda per capita, cujo coeficiente deixa de ser significativo no modelo completo (modelo 5). Já o coeficiente associado ao índice de condição social se mantém robusto com a introdução das variáveis relacionadas à taxa de homicídio e às políticas educacionais. Mais ainda, como podemos ver a partir dos coeficientes padronizados, esta variável se mostra um dos principais fatores explicando os diferentes desempenhos dos municípios no primeiro segmento do ensino fundamental.

Por fim, a taxa de homicídio e a municipalização do ensino fundamental exercem um efeito negativo, estatisticamente significativo mesmo que moderado, e o atendimento a pré-escola um efeito positivo sobre o IDEB urbano de $1^{\text {a }}$ fase. Essas variáveis mostram que, além das condiçóes socioeconômicas, a coesão social e a adoção de certas políticas educacionais, também exercem impacto sobre a qualidade da educação pública oferecida pelos municípios. 
Para os propósitos desse trabalho, chamamos atenção para o comportamento da primeira variável, o pertencimento aos 15 aglomerados urbanos com funções metropolitanas, frente à introdução das demais variáveis. Em todos os modelos os coeficientes para esta variável sáo negativos, isto é, pertencer a estes aglomerados urbanos exerce um efeito negativo, mesmo que moderado, sobre a qualidade da educação pública oferecida nos municípios. Além disso, o coeficiente dessa variável se torna mais negativo quando controlado por variáveis relacionadas às condiçóes socioeconômicas (modelos 2 e 3 ) e menos negativo quando as variáveis relacionadas à violência e à políticas educacionais dos municípios são introduzidas (modelos 4 e 5). Como vimos anteriormente, a variável taxa de homicídio por 100.000 habitantes é maior nos municípios metropolitanos nas regiōes Nordeste, Sudeste, Sul e Centro-Oeste e o atendimento a educação infantil é menor nos municípios metropolitanos de todas as regiôes do país. Portanto, podemos interpretar que estas variáveis relacionadas à tensão social e às políticas educacionais dos municípios estão explicando parte do efeito-metrópole.

A taxa de homicídio pode ser compreendida como um indicador da crise da sociabilidade típica das regiôes metropolitanas. Já a taxa de atendimento à pré-escola pode ser compreendida como um indicador não só de uma escolha de política educacional, como também da capacidade do município de atender ou investir neste nível de educação, tendo em vista que a LDB de 1996 priorizou e a instituiçáo do FUNDEF incentivou o atendimento do Ensino Fundamental pelos municípios ${ }^{17}$.

A escolha das prioridades desses municípios, ou a menor importância dada à educação infantil, podem estar relacionadas à competiçáo com outras demandas urbanas ou com outras áreas que são capazes de galvanizar mais votos para as lideranças políticas no poder. Processo que pode ser compreendido a partir da lógica dos "votos com os pés".

No quadro 5 observamos regressōes lineares estimando o IDEB 2005 para o segundo segmento do ensino fundamental. 
QUADRO 5. REGRESSÕES LINEARES ESTIMANDO IDEB 2005 - TOTAL URBANO $2^{a}$ FASE

\begin{tabular}{|c|c|c|c|c|c|c|c|c|c|c|}
\hline & & Modelo 1 & Modelo 2 & & Modelo 3 & & Modelo 4 & & Modelo & \\
\hline \multirow{2}{*}{ Regiōes Metropolitanas } & Coef & $-0,248 \quad * * *$ & $-0,264$ & $* * *$ & $-0,283$ & $* * *$ & $-0,227$ & $* * *$ & $-0,147$ & $* * *$ \\
\hline & Coef Padr & $-0,183$ & $-0,195$ & & $-0,209$ & & $-0,169$ & & $-0,109$ & \\
\hline \multirow{2}{*}{ Regiões Norte ou Nordeste } & Coef & $-1,008 \quad * * *$ & $-0,968$ & $* * *$ & $-0,541$ & $* * *$ & $-0,577$ & $* * *$ & $-0,581$ & $* * *$ \\
\hline & Coef Padr & $-0,739$ & $-0,709$ & & $-0,396$ & & $-0,421$ & & $-0,423$ & \\
\hline \multirow{2}{*}{ PIB per capita } & Coef & & 0,0000099 & $* * *$ & 0,00000275 & & 0,00000428 & & $-0,000002$ & \\
\hline & Coef Padr & & 0,113 & & 0,031 & & 0,049 & & $-0,023$ & \\
\hline \multirow{2}{*}{ Renda per capita } & Coef & & & & 0,001 & $* * * *$ & 0,001 & $* * *$ & 0,001 & $* *$ \\
\hline & Coef Padr & & & & 0,224 & & 0,207 & & 0,134 & \\
\hline \multirow{2}{*}{ Índice de condição social } & Coef & & & & 0,764 & $* * *$ & 0,739 & $* * *$ & 0,719 & $* * *$ \\
\hline & Coef Padr & & & & 0,234 & & 0,222 & & 0,216 & \\
\hline \multirow{2}{*}{$\begin{array}{c}\text { Taxa de homicidio por } \\
100.000 \text { hab }\end{array}$} & Coef & & & & & & $-0,003$ & $* * *$ & $-0,002$ & $* * *$ \\
\hline & Coef Padr & & & & & & $-0,134$ & & $-0,094$ & \\
\hline \multirow{2}{*}{$\begin{array}{l}\text { Municipalização do Ensino } \\
\text { Fundamental }\end{array}$} & Coef & & & & & & & & 0 & \\
\hline & Coef Padr & & & & & & & & $-0,012$ & \\
\hline \multirow{2}{*}{ Atendimento à pré-escola } & Coef & & & & & & & & 0,602 & $* * *$ \\
\hline & Coef Padr & & & & & & & & 0,279 & \\
\hline Constante & & $3,928 \quad * * *$ & 3,853 & $* * *$ & 2,918 & $* * *$ & 3,02 & $* * *$ & 2,83 & $* * *$ \\
\hline $\mathrm{R}^{2}$ & & 0,543 & 0,556 & & 0,625 & & 0,641 & & 0,703 & \\
\hline
\end{tabular}

$* \mathrm{p} \leq 0,05 * \mathrm{p} \leq 0,01 * \mathrm{p} \leq 0.001$

Em geral, observamos tendências parecidas com aquelas encontradas para o primeiro segmento do ensino fundamental (IDEB 2005 - urbano de $1^{\text {a }}$ fase). Entretanto, podemos observar algumas nuances.

Em primeiro lugar, o efeito-metrópole parece exercer um impacto mais acentuado sobre a qualidade deste segmento do ensino fundamental nos municípios. Estar integrado à dinâmica metropolitana significa uma diminuição em torno de 0,25 no IDEB urbano de $2^{\text {a }}$ fase dos municípios. Neste caso os coeficientes da variável renda per capita se mantêm robustos com a introdução das variáveis relacionadas à taxa de homicídio e às políticas educacionais dos municípios. A taxa de homicídio e o atendimento à pré-escola também se mantém como variáveis explicando o IDEB, entretanto a variável taxa de municipalização do ensino fundamental não parece exercer efeito sobre o IDEB de $2^{\text {a }}$ fase dos municípios. Este achado é compreensível dado que, na maioria dos casos, os processos de municipalização do ensino fundamental concentraram-se no primeiro segmento do ensino fundamental. O atendimento ao segundo segmento do ensino fundamental público ainda é função exercida principalmente pelos governos estaduais.

No que diz respeito ao efeito-metrópole, observamos novamente que os coeficientes relativos à variável integração à dinâmica metropolitana se tornam mais negativos com a introdução das variáveis relacionadas às condiçóes socioeconômicas (modelos 2 e 3) e menos negativos quando introduzimos as variáveis relacionadas à tensão social e às políticas educacionais (modelos 4 e 5). Novamente estes resultados nos sugerem que a crise de sociabilidade e os padróes de atendimento à pré-escola característicos das regióes metropolitanas estariam explicando parte do efeito-metrópole sobre a qualidade do ensino oferecida pelos municípios. 
Por fim, considerando que as diferenças de resultados entre municípios metropolitanos e nãometropolitanos se concentram nas regióes Sul, Sudeste e Centro-Oeste, realizamos análises levando em conta somente os municípios destas regióes.

\section{QUADRO 6. REGRESSÕES LINEARES ESTIMANDO IDEB 2005 - TOTAL URBANO 1ª FASE PARA OS MUNICÍPIOS DAS REGIÕES SUDESTE, SUL E CENTRO-OESTE}

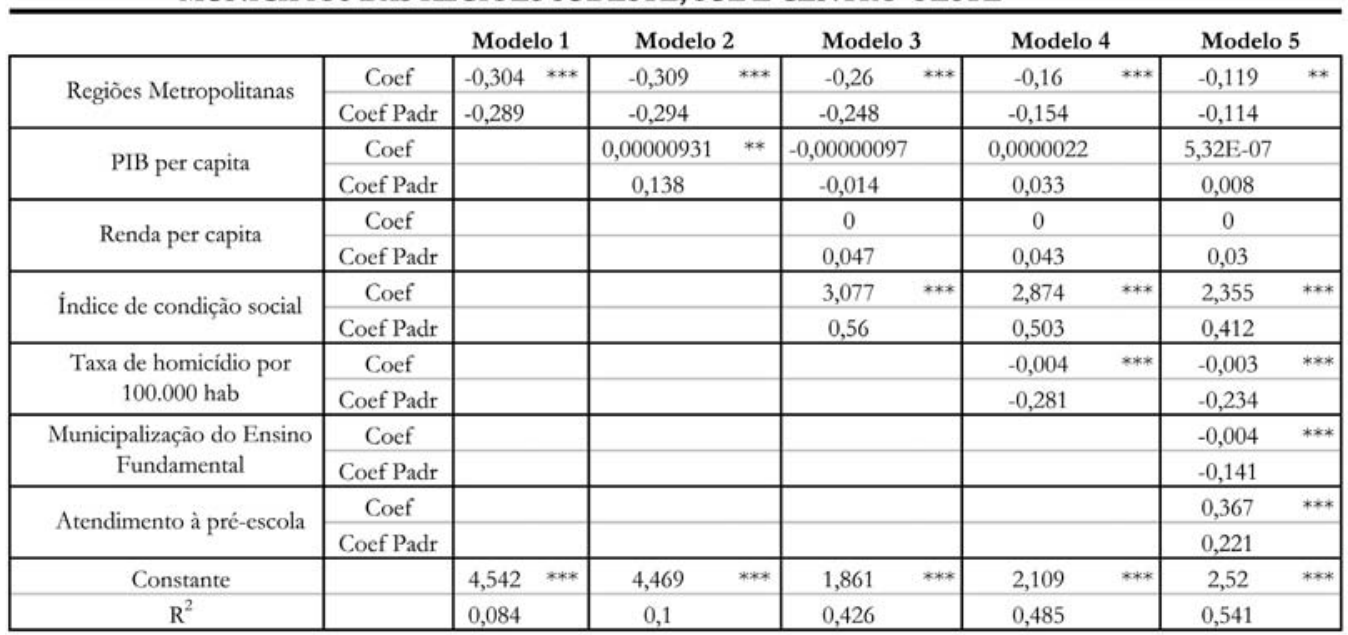

${ }^{*} \mathrm{p} \leq 0,05 * * \mathrm{p} \leq 0,01 * * * \mathrm{p} \leq 0.001$

QUADRO 7. REGRESSÕES LINEARES ESTIMANDO IDEB 2005 - TOTAL URBANO $2^{a}$ FASE PARA OS MUNICÍPIOS DAS REGIÕES SUDESTE, SUL E CENTRO-OESTE

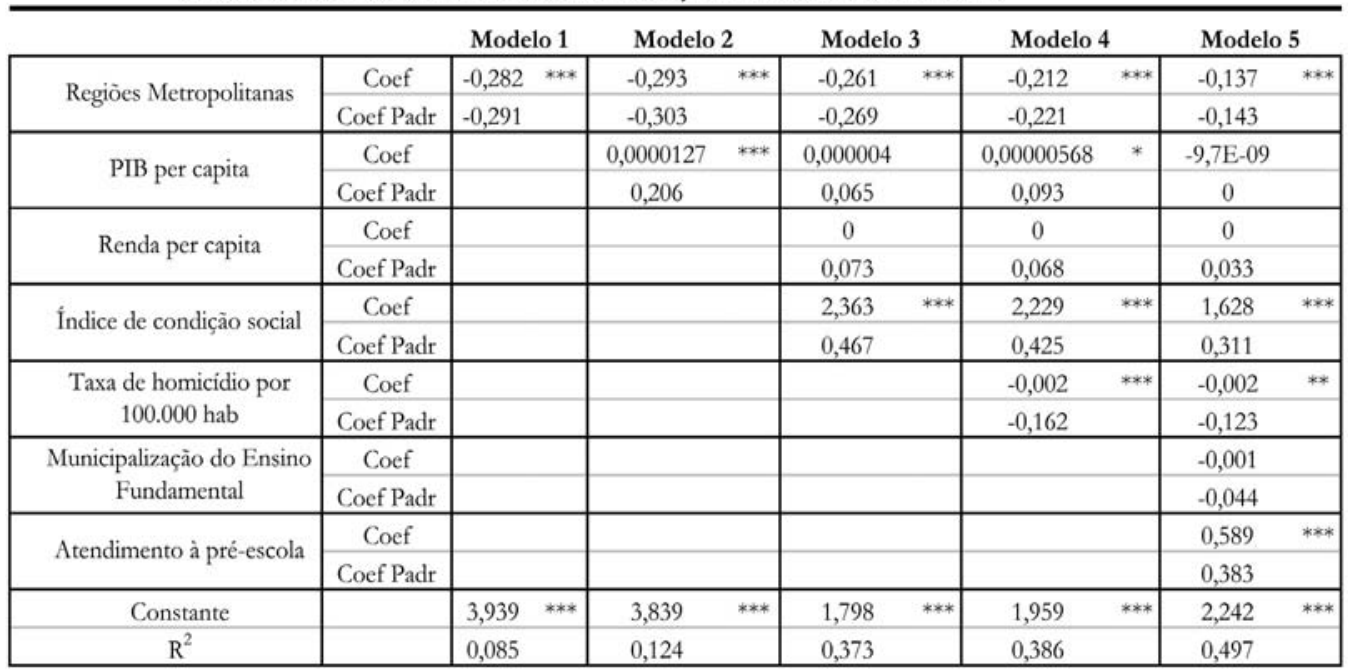

${ }^{*} \mathrm{p} \leq 0,05 * * \mathrm{p} \leq 0,01 * * * \mathrm{p} \leq 0.001$

Nos quadros 6 e 7 observamos os resultados de regressóes lineares estimando os IDEBs urbano de $1^{\text {a }}$ fase e de $2^{\text {a }}$ fase para os municípios das regióes Sul, Sudeste e Centro-Oeste. Observamos que estar integrado à dinâmica metropolitana exerce um impacto ainda mais negativo: significa, em média, uma diminuição em torno de 0,30 no IDEB de $1^{\text {a }}$ fase e de 0,28 no IDEB 
de $2^{\text {a }}$ fase destes municípios. Novamente, o PIB per capita não se mantém robusto com a introdução de outros indicadores relacionados às condiçóes socioeconômicas (modelos 3), à taxa de homicídio (modelos 4) e às políticas educacionais (modelo 5). A renda per capita também não parece exercer impacto sobre os resultados tanto do IDEB de $1^{\text {a }}$ fase quanto de $2^{a}$ fase. Novamente o índice de condição social se mostra como uma variável robusta, e com alto poder de explicação dos IDEBs referentes aos dois segmentos do ensino fundamental.

Ao restringirmos a análise às três regióes acima mencionadas, observamos um maior impacto da taxa de homicídio, especialmente sobre o IDEB urbano de $1^{\text {a }}$ fase dos municípios, se comparado com o modelo que leva em conta as 5 regióes (o coeficiente padronizado para esta variável no modelo 5 do quadro 6 é $-0,28$, enquanto no modelo que leva em conta os municípios de toda região - modelo 5 do quadro 4 - este coeficiente é equivalente a -0,14).

Já no que diz respeito ao impacto da pré-escola (modelos 5 dos quadros 6 e 7), observamos uma tendência similar à análise que levou em conta os municípios de todas as regióes. Novamente, a taxa de municipalização parece exercer um impacto negativo sobre o IDEB de $1^{\text {a }}$ fase, mas este efeito não é observado sobre o IDEB de $2^{\text {a }}$ fase.

Chamamos atenção para uma pequena diferença no comportamento do coeficiente da variável referente à integraçáo à dinâmica metropolitana. Em ambas as análises, apresentadas nos quadros 6 e 7, o coeficiente se mantém praticamente o mesmo com a introdução da variável PIB per capita (modelo 2). Entretanto, o efeito desta variável se torna menos negativo já no modelo 3, quando a variável índice de condição social é introduzida. Esta tendência é novamente observada com a introdução das variáveis taxa de homicídio e aquelas relacionadas às políticas educacionais.

Neste caso, novamente, a crise de sociabilidade bem como a competição por prioridades nas políticas urbanas que concorrem com a educaçáo infantil, parecem explicar parte do efeitometrópole. Entretanto, a condição social dos municípios, ou a concentração de pobreza e de domicílios com serviços inadequados de instalação sanitária, coleta de lixo e abastecimento de água, também explica a diferença dos resultados educacionais entre municípios metropolitanos e não-metropolitanos. Vale lembrar que essa diferença no índice de condição social, como situação inferior para os municípios localizados nas regióes metropolitanas, é especialmente acentuada no estado de Goiás, e segue o mesmo padrão, mesmo que de maneira menos acentuada, nos estados de São Paulo, Rio de Janeiro e Minas Gerais. Isto é, o menor índice de condição social compóe a realidade das regióes metropolitanas, e exerce impacto sobre a qualidade da educação oferecida pelos municípios metropolitanos situados nessas regióes.

\section{Comentários finais}

Nesse trabalho constatamos evidências sobre os fatores que incidem sobre o acesso às oportunidades educacionais, observados a partir da qualidade do ensino fundamental oferecido no âmbito dos municípios. Além das disparidades regionais, foi observada tendência de 
menor desempenho educacional nos municípios integrados à dinâmica metropolitana, mais acentuada nas Regióes Sudeste, Sul e Centro-Oeste. Formulamos a seguir um conjunto de hipóteses que permitiriam interpretar tais resultados, à luz do esboçado na primeira parte deste trabalho a respeito da vigência nas metrópoles brasileiras dos efeitos da crise do modelo dual de bem-estar social e da legitimidade dos padróes de interação social vigentes na fase anterior do nosso desenvolvimento.

Antes, contudo, impóem-se avaliar - ainda que sumariamente- se os resultados obtidos decorreriam da maior velocidade do grau de universalização alcançado nas metrópoles, comparativamente aos outros municípios, o que significaria que os piores indicadores da qualidade do ensino básico naquelas áreas resultariam da maior presença de crianças oriundas de meios sociais populares. Segundos dados das PNAD's - gráfico 5 - já tinha sido alcançada em 2006 tanto no Brasil metropolitano como no Brasil como um todo ${ }^{18}$ a virtual universalização do atendimento escolar para crianças de 7 a 14 anos (idade própria para freqüentar o ensino fundamental). Entretanto, a progressão destes dados mostra que, em 1992, nas regióes metropolitanas consideradas pelo IBGE, $88,9 \%$ das crianças já freqüentavam a escola, enquanto no Brasil esta porcentagem era de somente $81,8 \%$. Esta progressão traz fortes indícios de que os esforços para aumentar o atendimento no ensino fundamental nos últimos 15 anos estiveram concentrados fora do Brasil metropolitano e, portanto, a expansão do atendimento não seria capaz de explicar a pior qualidade da educação oferecida nos municípios integrados à dinâmica metropolitana. Estes, na verdade, já estariam a mais tempo mais próximos da meta de universalizar o atendimento ao ensino fundamental.

\section{GRÁFICO 5. PORCENTAGEM DE CRIANÇAS (ENTRE 7 E 14 ANOS) QUE FREQÜENTAM A ESCOLA}

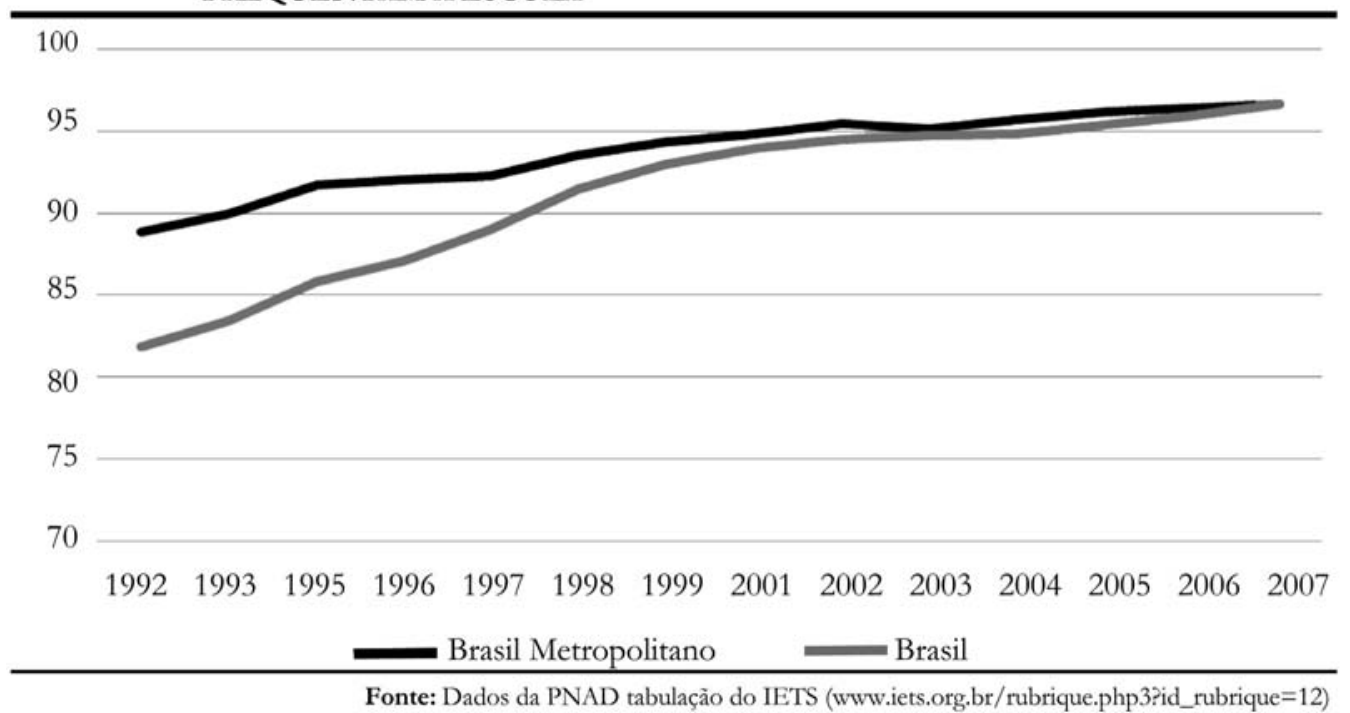

Fonte: Dados da PNAD tabulação do IETS (www.iets.org.br/rubrique.php3?id_rubrique=12)

18 É importante notar que os dados para o Brasil também englobam também as regiões metropolitanas. 
A nossa principal hipótese interpretativa decorre dos efeitos desorganizadores e desestabilizadores da vida social nas metrópoles, especialmente nos territórios que agrupam as camadas populares, decorrentes da transição de modelo de desenvolvimento que atravessamos.

Antes de explorar essas hipóteses à luz dos resultados empíricos obtidos nesse trabalho, convêm algumas observaçóes preliminares. Como é conhecido na literatura da sociologia da educação o sucesso escolar na fase do ensino básico - traduzido na efetiva aprendizagem e na realização do percurso escolar adequado - depende da aquisição pela criança de um conjunto de prédisposiçóes adquiridas na esfera de socialização primária, na forma de "esquemas de percepção, de julgamento, de avaliação, e a maneira pela qual estes esquemas podem "reagir" quando "funcionam" em formas escolares de relaçóes sociais" (Lahire, 2004, p.19). A aquisição de tais pré-disposiçóes é condicionada fortemente pelas configurações familiares cujo funcionamento permite a criança ser socializada na cultura escrita, tanto no que diz respeito à sua forma de expressão como também ao seu valor social e na interação social fundada na normatividade própria dos espaços morais. Por outro lado, como já mencionado anteriormente, a eficácia e a equidade do processo de educaçáo depende também de um conjunto de atributos e condições materiais e imateriais propicia ao surgimento de um contexto institucional favorável à transmissão da cultura letrada. Esses dois aspectos do processo de escolarização teorizado através do conceito de educabilidade (Lopes, 2005; 2008) permitem pensar a articulação dos fatores que ajustam ou desajustam os contextos sociais nos quais as crianças adquirem aquelas pré-condiçôes mencionadas e os que presidem a organização e funcionamento da escola como espaços institucionais e organizacionais nos quais as práticas de transmissão são realizadas. Estes dois contextos sociais - familiar e o da escola - de cuja relação decorre a educabilidade das crianças são fortemente influenciados pela dinâmica que preside a vida social nas grandes cidades, embora não exclusivamente. Com efeito, como mencionamos na primeira parte desse trabalho, um vasto conjunto de investigaçóes empíricas, sobre o funcionamento da escola, que identificamos constituindo a terceira geração, vem destacando a importância do contexto social conformado pela organizaçáo sócio-territorial das grandes cidades como também incidindo no processo de construçáo da educabilidade das crianças. Não se trata apenas da inevitável conseqüência do processo de urbanização das sociedades, mas dos efeitos combinados decorrentes do des-assalariamento, da fragilização da organização familiar e comunitária e mecanismos de segmentação e segregação residenciais dos vulnerabilizados pelo novo modelo de desenvolvimento. Tal combinação conformaria um dos traços distintivos da vida social nas grandes cidades que foram o núcleo econômico da grande indústria.

Os resultados empíricos obtidos neste trabalho vão nesta direção. Os dois indicadores que sintetizam o efeito metrópole estão relacionados com aspectos que podemos associar à constituição de contextos familiares-domicilares desfavoráveis à aquisição das pré-condições necessárias à incorporação da cultura letrada à sua transmissão pela Escola. O índice de condição social, com efeito, sintetiza os efeitos da fragilização dos laços com o mercado de trabalho entre os quais o mais relevante talvez não seja tanto o baixo nível de renda, mas a sua instabilidade por decorrer de expedientes para obter o sustento do núcleo familiar fundadas nas ocupaçóes informais e provavelmente ocasionais. Por outro lado, como o segundo componente desse 
índice é constituído pelas condiçóes de moradia, certamente ele está evidenciando a precariedade do habitat urbano, expresso pela ausência e deficiência dos serviços urbanos necessários à vida no grande centro urbano. Estes dois aspectos apontam para a existência de condiçóes materiais e sociais desfavoráveis ao funcionamento da unidade familiar-domiciliar como instância construtora das pré-condiçóes mencionadas. Vários trabalhos ${ }^{19}$ sobre a organização social do território das metrópoles brasileiras, por outro lado, vêm evidenciando o fenômeno da segregação residencial e a constituição de espaços de concentração de moradias precárias

O resultado da relação inversa entre a qualidade do ensino e a taxa de homicídios nos mostra outra faceta deste contexto social. Vários especialistas sobre o tema da criminalidade violenta fortemente incidente nas aglomerações urbanas metropolitanas brasileiras identificam relações entre este fenômeno e as tendências de desestabilização e desorganização sociais, além de apresentarem uma distribuição territorial tendente a coincidir com a geografia social da população vulnerável. Soares (2000), por exemplo, identificou entre os efeitos da criminalidade violenta nas favelas do Rio de Janeiro a desorganização da vida familiar e associativa, além de disseminar um ethos fortemente contraditório com as pré-disposiçóes requeridas pela Escola para a transmissão da cultura letrada. Com efeito, "nas favelas do Rio, o início do século XXI coincide com o predominio regressivo dos valores da guerra feudalizada: a hegemonia masculina afirma-se, paralelamente, à supremacia da coragem e da lealdade, sempre restritas às artes da guerra e ao âmbito hierarquizado e excludente do grupo de referência, o que corresponde à afirmação de um quadro explosivo de faccionalismo fratricida." (Soares, 2000, p.271) Tais valores incentivam o comportamento social dos jovens, com inevitáveis influências sobre os mais novos, em direção oposta a um dos principais elementos da disposição subjetiva a que vimos nos referindo. Trata-se da incorporação pelos indivíduos daqueles valores civilizatórios descritos por Norbert Elias (1993), que conformam indivíduos preparados para orientarem sua vida com base no "respeito às regras da sociabilidade; a racionalidade estrategicamente orientada, que habilita o seu portador a manipular relaçóes, administrar expectativa, que capacita quem a desenvolve a divisar intençóes ocultas sob a máscara das palavras e a dissimulação dos gestos" (Soares, 2000:270) A criminalidade violenta desencadeia, portanto a emergência de uma "cultura de rua" (Van Zanten, 2000) competitiva com a escola e a família na conformação da disposição das crianças e dos jovens.

Por último, o efeito metrópole sobre o pior desempenho das escolas pode também ser atribuído ao tipo de política educacional praticada pelos municípios que integram estas aglomeraçóes. $\mathrm{O}$ aspecto mais relevante é o fato desses municípios adotarem com menor freqüência a programas de ensino pré-escolar, ao mesmo tempo em que os nossos resultados confirmam o que outros trabalhos já constataram a respeito dos seus efeitos altamente positivos sobre o desempenho escolar. Por outras palavras, quanto mais cedo as crianças são expostas ao processo de transmissão da cultura letrada, maiores serão as chances de melhorar a qualidade do ensino fundamental. O pouco empenho dos governos municipais das metrópoles deve-se, muito provavelmente, ao fato da forte competição entre a educação e as prementes necessidades urbanas. Estas são objeto de pressóes políticas tanto pela via da reivindicação da população, quanto da mobilização do aparato político por seu potencial de geração de votos. Mais ainda,

19 Entre outros, Marques e Torres (2004); Ribeiro (2004; 2007). 
o estabelecimento de prioridades, muitas vezes, é realizado a partir de retornos eleitorais, ou da lógica dos "votos com os pés": a escola não dá voto e nem altera o grau de legitimidade das elites locais. A vigência dessa lógica político-eleitoral explica a razão pela qual a política educacional se transforma em política de assistência social em muitos municípios, ou seja, a escola se transforma em aparato de gestáo assistencialista das crianças e jovens oriundos dos meios populares diante da fragilização da família e as outras instâncias de socialização.

\section{Referências bibliográficas}

Ainsworth, J. W. (2002). Why does it take a village? The mediation of neighborhood effects on educational achievement. Social Forces, 81(1), 117-152.

Alves, F. (2007). Qualidade na Educação Fundamental Pública nas Capitais Brasileiras: tendências contextos e desafios. Tese de Doutorado, Faculdade de Educação, PUC/RJ.

Alves, F., Franco, F.C., Ribeiro, L.C.Q. (2008). Segregação Residencial e Desigualdade Escola no Rio de Janeiro, en L.C.Q. Ribeiro \& R. Kaztman (Eds.). A Cidade contra a Escola. Segregação urbana e desigualdades educacionais em grandes cidades da América Latina. Rio de Janeiro: Letra Capital, FAPERJ, IPPES.

Bourdie, Pierre. (1997). A Miséria do mundo. Rio de Janeiro: Vozes.

Brooks-gunn, J., Duncan, G. J. \& Aber, J. L. (Eds.) (1997). Neighborhood Poverty: context and consequences for children. Vol 1. New York: Russell Sage Foundation.

Crane, J. (1991). The Epidemic Theory of Ghettos and Neigborhood Effects on Dropping Out and Teenage Childbearing. The American Journal of Sociology, 96(5),1226-1259.

Cury, C. R. J. (2006). Legislação educacional Brasileira. Rio de Janeiro: DP\&A.

Damatta, R. (1981). Carnavais, Malandros e Heróis. Rio de Janeiro: Zahar.

Damatta, R. (1991) A casa e a rua. Rio de Janeiro: Guanabara Koogan.

Ellen, I.G. \& Turner, M.A. (1997). Does Neighborhood Matter? Assessing Recent Evidence. Housing Policy Debate. 8(4).

Fernandez, R. (2007). Índice de Desenvolvimento da Educação Básica (IDEB). Brasilia: INEP.

Filgueira, F. (1998). El nuevo modelo de prestaciones sociales en América Latina: residualismo, eficiencia y ciudadanía estratificada, en B. Roberts (Ed.) Ciudad y Política. San Jose de Costa Rica: FLACSO/SSRC.

Flores, C. (2008). Segregação residencial e resultados educacionais na cidade de Santiago do Chile, en L. C. Q. Ribeiro \& R. Kaztman (Eds.) A cidade contra a escola? Segregação urbana e desigualdades educacionais em grandes cidades da América Latina. Rio de Janeiro: Letra Capital.

Forquin, J.C. (1995), A sociologia das desigualdades de acesso à educação: principais orientaçóes, principais resultados desde 1965, en J.C. Forquin (Ed.) Sociologia da educação: Dez anos de pesquisas. Petrópolis: Vozes.

Elias, N. (1993). O processo civilizador. Rio de Janeiro: Jorge Zahar Editor.

Esping Andersen, G. (1999). Social Foundations of Post Industrial Economies. Oxford: Oxford University Press.

Garner, C.L., raudenbush, S.W. (1991). Neighborhood effects of educational attainment: a multilevel analysis. Sociology of Education, 64, 251-262. 
Jencks, C. \& Mayer, S. (1990). Residential Segregation, Job Proximity, and Black Job Opportunities, en L.E. Lynn, M.G.H. Mcgeary (Eds.). Inner-City Poverty in the United States. Washington, D. C.: National Academy Press.

Karabel, J., Halsey, A.H. (1977), Education research: a review and an interpretation, en J. Karabel \& A. Halsey (Eds.). Power and ideology in education. New York: Oxford University Press.

Kaztman, R., Retamoso, A. (2008). Aprendendo juntos. Desafios na educação a partir dos procesos de segregação urbana, en L. C. Q. Ribeiro \& R. Kaztman, (Eds.). A cidade contra a escola? Segregação urbana e desigualdades educacionais em grandes cidades da América Latina. Rio de Janeiro: Letra Capital.

Koslinski, M.C. (2000). O processo de implementação de políticas sociais descentralizadas. Dissertação de Mestrado, Faculdade de Educação, UNICAMP.

Lopes, N. (2005). Equidade educative y desigualdad social. Desafíos de La educación em el nuevo scenrio latinoamericano. Buenos Aires: IIPE-UNESCO

Lopes, N. (2008) A escola e o bairro. Reflexóes sobre o caráter territorial dos processos educacionais nas cidades, en L.C.Q. Ribeiro \& R. Kaztman (Eds.). A Cidade contra a Escola. Segregação urbana e desigualdades educacionais em grandes cidades da América Latina. Rio de Janeiro: Letra Capital, FAPERJ, IPPES.

Lee, V., Franco, F.C., \& Alabernaz, A. (2004). Quality and Equality in Brazilian Secondary Schools: A Multilevel Cross-National School Effects Study. Trabalho apresentado na 2004 Annual Meeting of the American Educational Research Association, San Diego.ultil

Marques, E. \& Torres, H. (2004). São Paulo, pobreza e desigualdades sociais. São Paulo: Editora SENAC-São Paulo.

Moura, R., Delgado, P.R., Deschamps, M.V., Castello Branco, M.L. (2007). O metropolitano no urbano brasileiro: identificação e fronteiras, en L.C.Q. Ribeiro \& O. Santos Junior (Eds.). As metrópoles e a questão social brasileira. Rio de Janeiro: Revan/Observatório das Metrópoles.

Mir, L. (2004). Guerra Civil, Estado e Trauma. São Paulo: Geração Editorial.

Peralva, A. (2000). Violência e Democracia: paradoxo brasileiro. São Paulo: Paz e Terra.

Reynolds, D., Teddlie, C., Creemers, B., Scheerens, J., Townsend, T. (2000). An Introduction to School Effectiveness Research, en C. Teddlie, D. Reynolds (Eds.). The International Handbook of School Effectiveness Research. London: Routledge.

Ribeiro, L.C.Q. (2004). Segregação residencial e segmentação social: o "efeito vizinhança" na reprodução da pobreza nas metrópoles brasileiras. Apresentado no seminário Internacional sobre Trabajo y Producción de la Pobreza en América Latina y el Caribe. Santa Cruz de la Sierra, Bolívia

Ribeiro, L.C.Q. (Ed.) (2004). Metrópoles: Entre a coesão e a fragmentação, a cooperação e o conflito. São Paulo: Editora Perseu Abramo.

Ribeiro, L.C.Q. (2007). A dimensáo metropolitana da questão social brasileira. Trabalho apresentado no $31^{\circ}$ Encontro Anual da ANPOCS, Caxambú.

Ribeiro, L.C.Q. \& Koslinski, M.C. (2009). Fronteiras Urbanas e Oportunidades Educacionais: $o$ caso do Rio de Janeiro. Trabalho apresentado na 33a Reunião Anual da ANPOCS, Caxambu-MG, Outubro, 2009. 
Sampson, R.J., morenoff, J. \& Gannnon-rowley, T. (2002). Assessing "Neighborhood Effects": Social processes and new directions in research. Annual Review of Sociology 28, 2002, p.443-478.

Small, L.M. \& Newman, E. (2001). Urban poverty after the Truly Disadvantaged: The rediscovery of family, neighborhood, and culture. Annual Review of Sociology, Vol 27, p.23-45.

Soares, J.F. (2002). Escola eficaz: um estudo de caso em três escolas da rede pública de ensino do estado de Minas Gerais. Belo Horizonte: GAME/FAE/UFMG.

Soares, J.F., Rigotti, J.I.R., Andrade, L.T (2008). As desigualdades socioespaciais e o efeito das escolas públicas de Belo Horizonte, en L.C.Q. Ribeiro \& R. Kaztman (Eds.). A Cidade contra a Escola. Segregaçâo urbana e desigualdades educacionais em grandes cidades da América Latina. Rio de Janeiro: Letra Capital; FAPERJ, IPPES.

Soares, L.E. (1997). A duplicidade da cultura brasileira, en J. Souza (Ed.). $O$ malandro e o protestante. A tese weberiana e a singularidade cultural brasileira. Brasília: Editora UNB.

Soares, L.E. (2000). Meu casaco de General. Rio de Janeiro: Companhia das Letras.

Souza, J. (2000). A modernidade seletiva. Uma reinterpretação do dilema brasileiro. Brasília: Editora da UNB.

Torres, H.G., Bichir, R.M., Gomes, S., Carpim, T.R.P. (2008). Educação na periferia de São Paulo: ou como pensar as desigualdades educacionais?, en L.C.Q. Ribeiro \& R. Kaztman (Eds.). A Cidade contra a Escola. Segregação urbana e desigualdades educacionais em grandes cidades da América Latina. Rio de Janeiro: Letra Capital; FAPERJ, IPPES.

Velho, G. (1996). Violência, reciprocidade e desigualdade, en G. Velho \& M., Alvito (Eds.). Cidadania e violência. Rio de Janeiro: Editora da UFRJ/ FGV.

Wilson, W.J. (1987). The Truly Disadvantaged: the inner city, the underclass and public policy. Chicago: University of Chicago Press.

Zanten, V.A. (2000). Cultura da rua ou cultura da escola. Revista Educação e Pesquisa, Vol. 26, no. 1, São Paulo, Jan/Junho. 


\section{Anexo. Outros gráficos}
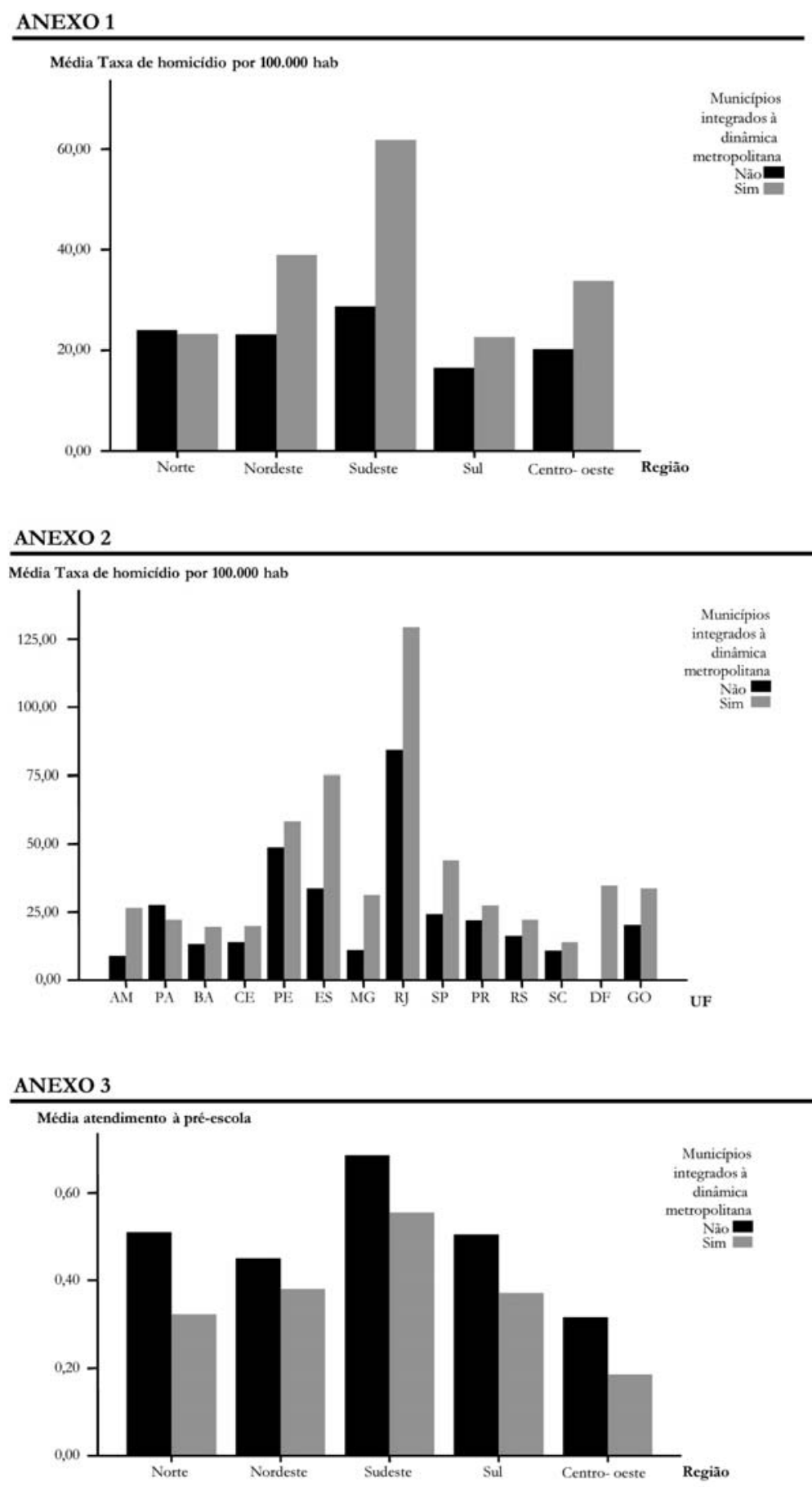


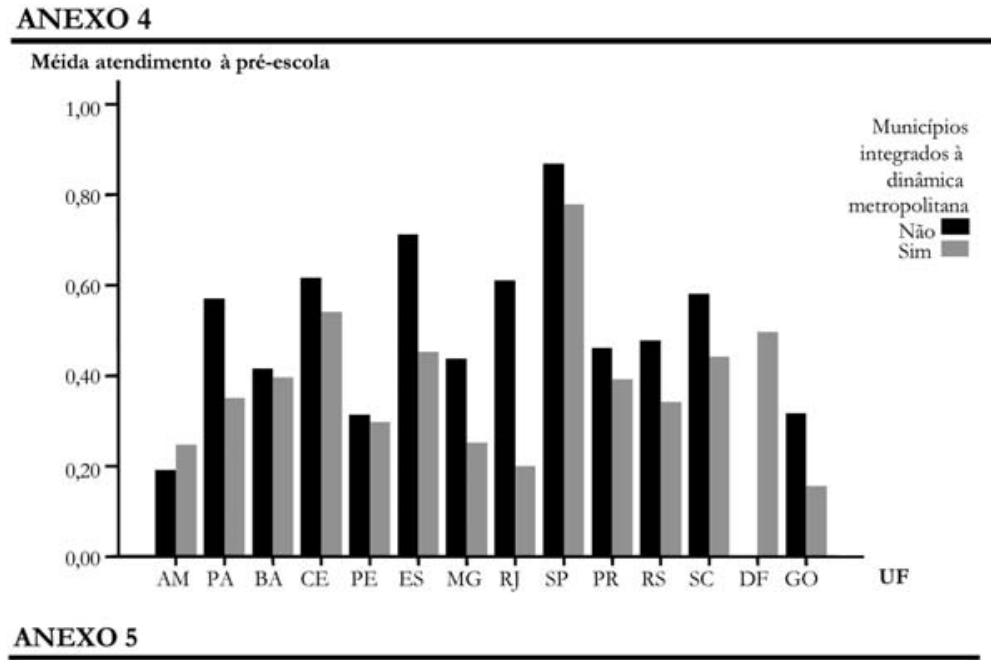

Média indice condição social
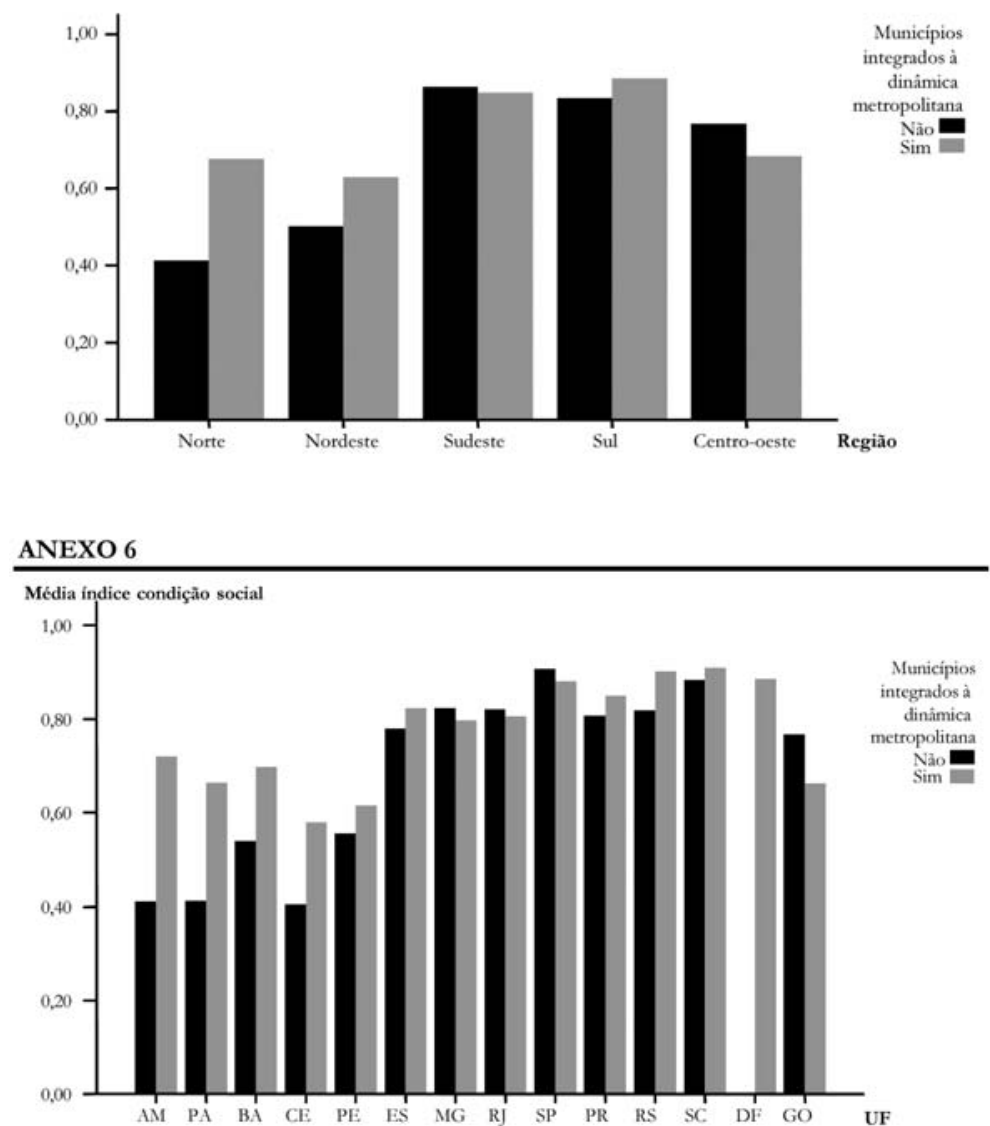
